\title{
Exploring Perceptions of Fighting on the College Campus Through a Gendered Lens
}

Hannah Liebreich

Follow this and additional works at: https://researchrepository.wvu.edu/etd

\section{Recommended Citation}

Liebreich, Hannah, "Exploring Perceptions of Fighting on the College Campus Through a Gendered Lens" (2014). Graduate Theses, Dissertations, and Problem Reports. 6084.

https://researchrepository.wvu.edu/etd/6084

This Thesis is protected by copyright and/or related rights. It has been brought to you by the The Research Repository @ WVU with permission from the rights-holder(s). You are free to use this Thesis in any way that is permitted by the copyright and related rights legislation that applies to your use. For other uses you must obtain permission from the rights-holder(s) directly, unless additional rights are indicated by a Creative Commons license in the record and/ or on the work itself. This Thesis has been accepted for inclusion in WVU Graduate Theses, Dissertations, and Problem Reports collection by an authorized administrator of The Research Repository @ WVU. For more information, please contact researchrepository@mail.wvu.edu. 
Exploring Perceptions of Fighting on the College Campus Through a Gendered Lens

Hannah Liebreich

Thesis submitted

to the College of Arts and Sciences

at West Virginia University

In partial fulfillment of the requirements for the degree of

Masters of Arts in

Sociology

Karen Weiss, Ph.D., Chair

Lisa Dilks, Ph.D.

Melissa Latimer, Ph.D.

Department of Sociology

Morgantown, West Virginia

2014

Keywords: Gender, violence, fighting, college masculinity, college femininity

Copyright 2014 Hannah Liebreich 


\section{ABSTRACT \\ Exploring Perceptions of Fighting on the College Campus Through a Gendered Lens}

\section{Hannah Liebreich}

This thesis explores gender and fighting on the college campus. Recent studies that focus on the behavior of college students establish that risky behaviors, such as fighting, occur and are often normalized by students on college campuses (Armstrong and Hamilton, 2013; Kimmel, 2008; Weiss, 2013; Wechsler and Wuethrich, 2002). While these studies concentrate primarily on the role alcohol plays in social situations and in a variety of risky behaviors, they focus more broadly on college student behavior. Using a micro level analysis within the context of gender and aggression on the college campus, this thesis aims to explore the way college students perceive gender and fighting. This thesis uses focus group data collected at a large North Central university to explore the way college students understand how building and defending a gendered reputation (i.e. the respect they gain by appropriately performing gender during confrontational social situations) is important in explaining why college men and women fight (Cobbina, Like-Haislip, Miller, 2010). This thesis contributes to campus culture literature and studies on college masculinity and college femininity by focusing exclusively on gender and fighting rather than a wide range of risky behaviors. The findings from this thesis suggest that while there are gender differences in how college students perceive fights between college men and women, participating in a fight is perceived as important to both college men and women's gendered reputations under certain circumstances. 


\section{Dedication}

This thesis is dedicated to the influential women in my family who inspire me to be a feminist sociologist. In loving memory of my grandmother: Ruth Morgan Sheppard January 31, 1922-October 11, 2014. 


\section{Acknowledgement}

I would like to thank and acknowledge all of the folks at West Virginia University who supported me while working on my MA thesis. I would especially like to thank Dr. Karen Weiss and my committee members for guiding me through this process. I would also like to thank my colleagues at the Women and Gender Studies Center for their support. 


\section{Table of Contents}

Chapter 1: Introduction

Chapter 2: Masculinities and Men’s Aggression

Chapter 3: Femininities and Women's Aggression

References 


\section{Chapter 1: Introduction}

According to traditional gender norms, aggressive behavior such as fighting has historically been reserved for boys and men, while physically passive aggression such as name-calling has been reserved for girls and women (Campbell, 1993; Jack, 1999). Given these pervasive traditional gender norms regarding aggression, this thesis explores how college students perceive college men and women who engage in the traditionally masculine behavior of fighting. Specifically this thesis focuses on one aspect of why college students fight by exploring the question: how is building and defending a gendered reputation perceived by college students as an important reason for explaining why college men and women fight?

For the purpose of this study, fighting is conceptualized as a physical attack with no clear victim or perpetrator, sometimes referred to as mutual combat (Weiss, 2013: 80). The term gendered reputation derives from a previous study that explores gender, aggression, and reputation in the context of gang violence (Cobbina et al., 2010). Gendered reputation refers to respect gained by appropriately performing gender norms in a confrontational situation (Cobbina et al., 2010). These two concepts, fighting and gendered reputation, serve as a foundation for the research question that guides this thesis. Throughout this thesis I will further contextualize the concept of gendered reputation, and I will explore the concepts of gender and gender norms. Then I will examine why this study is important by providing examples of the ways in which some college students have expressed concern over campus fights. Additionally, I will conceptualize partying on college 
campuses by exploring literature on college campus culture and defining the term party subculture. The introduction, as well as well as subsequent chapters, will also focus on previous studies and the explanations they provide for why some young people engage in aggressive behavior.

\section{Gendered Reputation}

In Cobinna et al.'s (2010) study of gender, aggression, and gang violence, the authors focus on the ways in which men and women appropriately demonstrate gender in terms of aggression during confrontation. The authors suggest that when gang members engage in aggressive behavior such as fighting, this behavior is a way for both young men and women to build their reputations because fighting is a way to show that an individual is tough (Cobbina et al., 2010). Although this study focuses on gender and gang violence rather than college men and women's use of aggression, it clearly defines and emphasizes the important relationship among gender, aggression, and reputation. This study is vital to this thesis because it provides a working definition of gendered reputation (Cobbina et al., 2010). Although Cobinna et al.'s (2010) study focuses on gang violence, this definition of gendered reputation (i.e. gendered reputation is the respect gained by appropriately performing gender norms) is applicable to many young people who fight because fighting and reputation building are not exclusive to gang members. 


\section{Gender and Gender Norms}

There are three distinct ways to conceptualize gender: biological essentialism, cultural construction, and power discourse (Greig, Kimmel, \& Lang, 2000). Biological essentialism looks at gender in terms of similarities in biological and anatomical body parts (i.e. penis or vagina, testosterone or estrogen, facial and body hair, and other physiological characteristics). In contrast to biological explanations, the idea that gender is culturally constructed is best explained as the cultural norms and social pressure that help to determine the roles, responsibilities, and relations that are available and imposed upon individuals based on their gender (Greig et al., 2000). The idea that gender is a power discourse suggests that understanding masculinity and femininity should encompass more than the biological or cultural basis of identity (Connell, 2000; Greig et al., 2000). In the power discourse concept of gender, society must understand gender in terms of the power relations between men and women (Connell, 2000; Greig et al., 2000). For a thesis that explores the way gender norms influence the perceptions of college students, it is important to steer clear of biological essentialism when conceptualizing gender. This way of thinking about men and women is problematic because it relies on the assigned sex at birth rather than a socially agreed upon understanding of what it means to be a man or a woman and masculine and feminine.

For the purpose of this thesis, it is critical to conceptualize gender as a social construct that varies cross-culturally, as it is likely that a variety of gender norms 
influence the perceptions of college students. It is also important to understand gender in terms of power discourse, or the relationship between gender and power, because studies on traditional gender norm suggest there are differences in expected behavior of men and women regarding the use of aggression (Campbell, 1993; Greig, Kimmel, Lang, 2000). Essentially, a power discourse approach is important to this thesis because different norms exist for men and women regarding the use of aggression, and this creates a relationship between gender and power ${ }^{1}$. These ways of thinking about gender, along with a micro level analysis of perceptions of gender norms are central to this thesis because traditional gender norms are formed and learned through the process of socialization ${ }^{2}$. It is through the socialization of traditional gender norms that members of a society learn appropriate masculine and feminine behavior, and an individual's understanding of appropriate gender behavior influences their perceptions.

Keeping with a micro level analysis, I rely on West and Zimmerman's (1987) work on "doing gender" to better understand the way gender influences social interactions. "Doing gender" suggests that individuals in society perform activities that constantly produce and adhere to gender norms which are subjected to assessment by society (West \& Zimmerman, 1987). The concept of "doing gender" suggests that gender is an integral part of all social exchanges (West \& Zimmerman, 1987). Similarly, Butler's (1988) work on gender performance explains gender as a performative act where social action requires a performance that is repeated. Victor

${ }^{1}$ The relationship between gender and power is further discussed in chapters 2 and 3 in terms of the gender hierarchy.

${ }^{2}$ The process where children as well as adults learn from one another. 
Turner reaffirms Butler's (1988) work on gender performance with the assertion that "this repetition is at once a reenactment and reexperiencing of a set of meanings already socially established; it is the mundane and ritualized form of their legitimation"' (qtd. in Butler, 1988: 526). Both West and Zimmerman (1987) and Butler (1988) establish the importance of gender within social interactions. Because gender is part of all social interactions, and gendered behavior is assessed by society, it is important that individuals learn gender appropriate behavior.

Since gender is present and an integral part of all social interactions, often individuals repeat gender appropriate behavior without being conscious of the gendered nature of their behavior. For this reason, it is important to explore the ways in which groups of people, including college students, understand gender in social interactions. This thesis focuses specifically on the way college students understand gender and fighting because previous studies on campuses with heavy partying suggest fights between college men and between women occur (Kimmel, 2008; Weiss, 2013) and are normalized (Weiss, 2013). For example, Kimmel (2008) found that for college men, fights are a popular way to prove masculinity. Meanwhile, Weiss (2013) found that students discussed fights between college women casually. While these previous studies on college student behavior establish that fights occur and are often normalized by students, articles published in the student-run newspaper where the data for this thesis was collected suggest that some students are concerned with fights on campus. 


\section{Fighting: Cause for Concern?}

While collecting data for this thesis, I found that the university's student newspaper published several articles on the topic of campus fights. There was an update on a high profile fight from the beginning of the school year where one participant was left in a coma and was facing the possibility of surgery for his injuries. Another article from the campus newspaper focused on plans for student government and university police officers to better patrol areas that were known to be dangerous because of fights. These articles from the campus newspaper describe the perspectives of concerned students, administrators, campus police, and community members. They serve to demonstrate that while many students normalize fighting, other individuals on campus are concerned about fights and student safety.

Weiss' study (2013) on party schools provides support for the notion that often college fights cause injury and are a potential risk to student safety. According to Weiss' analysis of Campus Crime Victimization Survey data, $41 \%$ of students who experience simple assaults suffered injuries (Weiss, 2013; 80). Although many students experience injuries because of simple assaults (which include fights), fights are still common and often normalized in the context of college parties (Weiss, 2013). In addition to causing injury, other students appear to be concerned about campus fights and student safety so this exploration of college fights is necessary. It is particularly vital to better understand how college students perceive fights with 
respect to the gender of the fight participants and their reputation because this will provide insight into one aspect of why fights occur (Weiss, 2013).

\section{The Party Subculture}

A subculture is a distinct social group that organizes around a shared set of interests and practices (Gelder \& Thornton, 1997). We, as a society, have a basic understanding of what is meant by the term "party school" because the Princeton Review publishes an annual list of the top party schools in the country. Party schools are glorified in the media and have received mainstream attention in large part because of the Princeton Review list, but for the purpose of this study it is important to clearly define the term party subculture. According to Weiss (2013), the party school has a "student-regulated cultural presence... characterized by extreme drinking, drug use and risk taking" (Weiss, 2013: xiv). The party subculture thrives under student behavior that is influenced by an extreme bar and party scene highlighted by drinking games and risky behavior (Weiss, 2013). Similarly, Armstrong and Hamilton (2013) describe a range of college pathways including the party pathway which refers to a subculture filled with “'beer and circus'” where drinking and recreational activities are prioritized (qtd. in Armstrong \& Hamilton, 2013: 15). With these definitions in mind, it would seem that the party school is a breeding ground for violent behavior because extreme drinking often leads to participation in fights and other risky behaviors.

In a typical night in the party subculture, students drink, party, and engage in risky behavior (Weiss, 2013). The college party subculture is a world where 
actors have an "anything goes" mentality because risky behavior is common, and alcohol is typically used to justify a variety of risky behaviors including fighting (Weiss, 2013). For example, Weiss' study (2013) suggests that because it is a fairly prevalent aspect of the party subculture, fighting is not uncommon for both college men and women. Similarly Armstrong and Hamilton (2013) suggest that the party scene is a "fast world, [where] fun, disappointment, and danger existed in exquisite tension" (Armstrong \& Hamilton, 2013: 74). The findings from Weiss (2013) and Armstrong and Hamilton (2013) suggest that students expect to have fun while attending college, and the damages that often result from risky behavior are minor, inconsequential setbacks to enjoying the college experience. These previous studies on college student behavior are important to this thesis because they contextualize party schools as well as the role risky behavior plays in the college experience (Armstrong \& Hamilton, 2013; Weiss, 2013). Previous literature also highlights the way risky behavior such as fighting is normalized in the context of the party subculture (Weiss, 2013).

Young men and women arrive annually to colleges across the United States to gain an education, but they also attend college because this experience is a rite of passage into adulthood. Many young people arrive at a large public university similar to the college that is the focus of this thesis, but earning an education may not be their only intended outcome (Armstrong \& Hamilton, 2013; Kimmel, 2008; Wechsler \& Wuethrich, 2004; Weiss, 2013). According to the National Center for Education, approximately 6.8 million students were enrolled at 4-year public universities in 2013 ("National Center for Education", 2014). Although there are a 
substantial number of students attending college, less than a quarter of expected graduates earned a bachelor degree in the same year ("National Center for Education", 2014). If many college students are not completing degrees or not completing their degree in the traditional four-five year time period, this suggests that students have other priorities while attending college beyond earning a degree. Armstrong and Hamilton's (2013) study that explores different college pathways suggests that the party pathway, the recreational and socializing aspect of college, is the most popular pathway and attracts many students compared to the pathway of academics. Many of the women in the authors' study, about one fifth, admitted the main appeal to their current college was the party reputation (Armstrong \& Hamilton, 2013: 28-29). With the party subculture being such an integral part of the college experience, research must continue to address party schools and the behavior that highlights this environment.

\section{Explanations for Fights}

There are a variety of reasons why college men and women participate in fights. Weiss (2013) found in her exploration of the party school that college students often participate in fights to "settle the score'" with another student, help out in an unfair fight, or to settle trivial verbal altercations (Weiss, 2013: 80-81). Additionally, some college students who engage in the party subculture actively pursue fights (Weiss, 2013). While Weiss' (2013) study provides insight into some explanations for why college students fight, this study does not examine the way gender norms influence college students' perceptions of why their peers fight. These 
explanations presented in Weiss' (2013) study are similar to findings from studies that explore fights among young people in other social environments. However, the influential role of gender in terms of perceptions of fights has been explored in the context of urban youths' aggression and working-class youths' aggression, but not in the context of college students (Brown \& Tappan, 2008; Chesney-Lind \& Jones, 2010; Day, Gough, \& McFadden, 2003; Ness, 2004). Additionally, the risky behavior of college students, which includes fighting, tends to be normalized while aggression among young people in other social climates often is not. This thesis fills a gap in the campus culture literature and the gender and fighting literature by exploring the way gender norms influence perceptions of college fights.

One study that explores men's use of aggression in the context of a night out found that often men fight because someone spilled a drink, someone bumped into them, or someone threatened their reputation (Benson \& Archer, 2002). Meanwhile, the findings from studies on fights between women in urban areas suggest that women fight to confront someone who is looking at them wrong, to survive their living environments, and to preserve their reputation (Brown \& Tappan, 2008; Chesney-Lind \& Jones, 2010; Day et al., 2003; Ness, 2004). As presented in the definition of gendered reputation, in terms of gender, fighting, and reputation, Cobbina et al. (2010) suggest that over time, for men in gangs violence has been a way to acquire respect and defend their reputation by demonstrating appropriate masculinity. This study also suggests that women in gangs use violence more often than commonly believed and that their behavior is also tied to status and respect (Cobbina et al., 2010). Previous studies suggest that many of the reasons used to 
describe why young men and women fight also relates to reasons given by college students (i.e. trivial reasons and reputation). While the motivation for fighting among young people appears to be similar in different social situations, it is unclear if the role of gender will be perceived the same way in the context of fighting and the college party subculture. The relationship between gendered reputation and fighting has been extensively explored in the context of diverse social climates, yet there is limited research on gender and fighting exclusively in the context of the party subculture. Because gender and reputation are often described in explanations for why young people in different environments fight, it is important to better understand how building and defending a gendered reputation is perceived by college students as an important reason for explaining why college men and women fight.

\section{Objectives}

For this thesis, I focus on the college campus and the party subculture because previous literature on gender and fighting often focuses on other environments such as urban areas (Chesney-Lind \& Jones, 2010; Cobbina et al., 2010; Ness, 2004) College students is a critical population to understand in terms of gender and the use of physical aggression because previous literature suggests that fights occur and are normalized in this environment, yet there are few studies that focus exclusively on this topic (Weiss, 2013). A better understanding of the way college students describe and make sense of fighting is crucial to the overall safety on college campuses because this risky and potentially dangerous behavior is 
common and often normalized by students. This thesis explores one aspect of why college students fight and examines the following research question:

How is building and defending a gendered reputation perceived by college students as an important reason for explaining why college men and women fight?

By providing insight into the research question that drives this study, I seek to offer a better understanding of the way gender norms influence college students' perceptions of fights. I am also interested in the way traditional gender norms influence and possibly contradict the reality of college fights according to the stories told by students.

In the next two chapters I will define the concepts masculinity and femininity and provide an overview of previous literature on traditional gender norms. These subsequent chapters will concentrate on masculinity and femininity and the use of aggression. I will also evaluate previous studies of fights between men and women focusing primarily on how these concepts and previous studies relate to college students and the use of aggression. It is essential to define masculinity and femininity and establish their relationship with aggression in the context of the college campus because this thesis aims to better understand the perceptions of students in terms of why college men and women fight with respect to their gendered reputation.

After defining key concepts and reviewing previous literature, I will present my methods and findings. I will discuss the ways in which the current data relates to my research question about college fights and gendered reputation, and I will also 
explain the way the current data relates to previous studies on gender and fighting. Finally, I will provide a conclusion to discuss future research related to the topic of gender and fighting in the context of the college campus and the limitations of this study. 


\section{Chapter 2: Masculinities and Men's Aggression}

Like gender, masculinity is socially constructed and a fundamental part of all social interactions. Because individuals constantly perform gender, often adhering to societal gender norms, it is important to understand how the terms "masculine" and "feminine" are socially constructed. This chapter focuses on masculinity, and the following chapter focuses on femininity as a social construct. This chapter begins by defining masculinity and traditional masculine gender norms and emphasizes the importance of aggression. I will review previous literature that evaluates traditional masculine gender norms and masculine identities for men within the context of aggression, fighting, and the college campus.

\section{Defining Masculinity and Hegemonic Masculinity}

It is essential to understand masculinity as a cultural construct because this establishes masculinity as a role that is performed based on cultural understandings of what it means to be a boy and man. This way of thinking about masculinity fits with Butler's (1988) work on gender performance because it explores the way gender norms are socially constructed and performed accordingly. For example, a defining characteristic of masculine behavior is that men are aggressive, so men often perform masculinity by engaging in aggressive behavior such as fighting (Butler, 1998; Campbell, 1993). The notion that masculinity is a social role performed by men and often leads to aggressive behavior works to explain what Greig et al. refer to as the "stereotypically problematic male behaviors, such as violence..." (Greig et al., 2000: 5). This assertion suggests that masculinity, 
aggression, and violence are linked by gender norms; and gender and violence can often be problematic when violence becomes part of the gender expectations for men. Understanding the relationship among masculinity, aggression, and violence as problematic behavior is critical to this thesis because I am interested in perceptions of why college students fight despite previous literature suggesting that this behavior is potentially dangerous (i.e. problematic). Linking aggression and violence to problematic gendered behavior provides a foundation for the exploration of why college fights persists despite the risk of injury.

The working definition of masculinity for this thesis conceptualizes the term based on cultural understandings of what it means to be masculine and what it means to perform masculine behavior as a man. This includes understanding the link between masculinity and aggressive behavior. While this working definition does conceptualize masculinity in terms of cultural appropriate gender behavior, this definition limits masculinity and aggressive behavior to men. When the concept of power discourse is applied to masculinity, it broadens masculine behavior to any behavior that society deems masculine, regardless of the gender of the performer. Power discourse assesses masculinity in terms of who is performing traditionally masculine behavior and the purpose that it serves (Greig et al., 2000). In the power discourse understanding of gender, both men and women can perform masculine behavior, and the gender of the social actor helps determine the purpose that their behavior serves. This way of thinking about gender and masculinity is significant because this study explores fighting, a behavior traditionally expected of men, but performed by both men and women. 
To build on this working definition of masculinity, I draw on Connell's notion of hegemonic masculinity. According to Connell (2000), hegemonic masculinity is the idea that there are multiple masculinities that can be ranked, and hegemonic masculinity is the most prized form of masculine behavior. Hegemonic masculinity can vary cross-culturally, but because it is the most prized form of masculine behavior, it ranks high on the gender hierarchy (Connell, 2000). In the working definition of masculinity used in this thesis, aggressive behavior is highly valued, so it is a defining characteristic of hegemonic masculinity (Campbell, 1993; Connell, 2000). Understanding the gender hierarchy produced by hegemonic masculinity is beneficial when using a power discourse approach to gender because hegemonic masculinity suggests that masculine behavior is dominant over feminine behavior (Connell, 2000). In order to better understand the significance of hegemonic masculinity as it relates to this thesis, I will further explore hegemonic masculinity and the gender hierarchy by focusing on the role of aggression and fighting.

Aggression and fighting are important behaviors in the hierarchy created by hegemonic masculinity because the use of physical aggression is a key way for men to express dominance over women and other men who rank lower in the hierarchy of gender and masculinities. The distinction of a plural masculinity is important to note because although masculinity is often referenced as a singular behavior, there are different ways of doing masculinity that we as a society rank and must recognize. If there are different experiences of masculinity, then it makes sense to pluralize the use of the word. Fighting is only one way for men to express aggression and for men to perform masculinity; not all men express masculinity in this manner 
(Campbell, 1993; Connell, 2000). However, according to previous literature on masculinity, men who participate in fights often rank higher on the gender hierarchy and have a higher status compared to men who are less aggressive (Connell, 2000). This also suggests that powerful men (i.e. those that have already achieved hegemonic masculinity) are not always violent and aggressive. Rather, men who lack power strive to attain it by engaging in aggressive behavior because aggressive behavior is a perceived way to build hegemonic masculinity and climb the gender hierarchy.

\section{Traditional Masculine Gender Norm and the Use of Physical Aggression}

Because masculine gender norms can vary cross-culturally, it is important to explore literature that defines behaviors and characteristics of socially agreed upon masculine gender norms. This will further reinforce the relationship between hegemonic masculinity and aggression. Masculine gender norms for boys and men perpetuate the social expectation that "there is a widespread belief that it is natural for men to be violent" (Connell, 2000: 215). Campbell (1993) explains that society teaches boys to view aggression as an issue related to dominance and masculinity. These findings from Connell (2000) and Campbell (1993) suggest that as a society we view boys and men's use of violence as normal, and we expect boys and men to use violence and aggression to express dominance and masculinity. When we apply these findings in terms of hegemonic masculinity, it is clear that a defining feature of ideal masculinity is often aggressive and violent behavior. 
Through positive reinforcement, men are socialized to express aggression and violence as a way of exercising power and control (Campbell, 1993; Connell, 2000). This suggests that when boys and men engage in violence and aggression, their behavior will be rewarded. Aggression and physical violence are parts of the very fabric of masculinity in that these behaviors are often synonymous with masculine gender norms. Connell (2000) best summarizes the connection between masculinity and violence in the observation that "We often see men involved in violence in order to prove their masculinity, or to defend their masculine honour, or to challenge others" (Connell, 2000: 218). Essentially, previous literature on traditional masculine gender norms suggests that demonstrating dominance and power through aggression and violence are socially agreed upon masculine behaviors boys and men are socialized to perform (Campbell, 1993; Connell, 2000; Kimmel, 2008). Additionally, aggression and fighting are social tools available to men as part of their gender performance of masculinity.

Although society may not always actively encourage men to express aggression physically, when men are presented with confrontational situations, often they are encouraged to respond physically. Traditional masculine gender norms provide men with access to more dominant and physical forms of expressing aggression including, but not limited to, fighting (Campbell, 1993; Connell, 2000). Men's use of physical aggression and violence can take many forms such as postulating to intimidate an opponent, throwing punches outside of a bar, or pulling a gun in a gang fight (Benson \& Archer, 2002; Brown \& Tappan, 2008; Cobbina et al., 2010). There are many ways men can perform masculinities that involve aggressive 
behavior so it is important to think of masculinity as fluid, plural, and hierarchical in terms of hegemonic masculinity. Because fighting is aggressive and aggression is often a defining feature of hegemonic masculinity, it ranks high on the masculine hierarchy. Often, men utilize fighting when they lack power and seek to gain a masculine reputation (Connell, 2000).

\section{Previous Studies: Hegemonic Masculinity, Aggression, and Fighting}

Given the close relationship between hegemonic masculinity, aggression, and violence, there are many gender norms that exist related to men's use of physical aggression and violence. In order to better understand the relationship between these concepts, it is important to focus on previous studies that explore masculinity in terms of fighting as this is a common way for men to attain hegemonic masculinity. Further exploration of masculine gender norms related to aggression and fighting provides insight into why some men fight and how it is justified. For example, when Connell (2000) evaluated masculine social constructs as they relate to violence and aggression, the researcher points to the common stereotype that men’s aggression such as fighting is just “'Boys being boys'” (Connell, 2000: 215). This phrase is often used to broadly justify boys and men who use aggression and violence in confrontational situations.

Similar to Connell (2000), Benson and Archer (2002) found that in a night out at the bar men are likely to experience conflict due to a variety of situations such as another man spilling a drink on him or looking at his girlfriend "wrong"'. These findings are similar in that for men, fighting a perpetrator is an acceptable and 
justified response in many confrontational situations. There are three key components of this finding from Benson and Archer's (2002) study. First, during social situations where conflict is involved, hostility and violence often serve as conflict resolution. Second, the motivation for the fight is often over an event that regularly occurs in a bar or party setting such as a spilled drink. Third, the findings suggest that men engage in fights at bars in order to protect their masculine status (i.e. when a man believes that a peer looks at him "wrong" this can be perceived as a challenge to his masculinity). The findings from Connell (2000) and Benson and Archer (2002) support the literature on traditional masculine gender norms in that aggression and fighting are ways to attain a masculine reputation (Campbell, 1993). The aggressive behavior of boys and men is often justified because aggression and violence are intricate parts of masculinity (Campbell, 1993).

Previous studies suggest that aggression and violence are justified forms of conflict resolution for men, and fighting often serves to influence a man's reputation because this behavior is traditionally masculine. Additionally, Lowe et al. (2012) suggest that engagement in physical aggression is a way to present masculinity in the social world because "for men aggression is a legitimate means of assuming control over the world around them" (Lowe et al., 2012: 1804). Findings from Connell (2000), Benson \& Archer (2002), and Lowe et al. (2012) reflect traditional masculine gender norms for men which dictate that aggression, violence, and fighting are integral to masculinity (Campbell, 1993). These studies provide insight into why men use aggression and fighting in different social contexts, but these findings do not directly explore college men's masculinity. The next section will 
focus on studies that examine college masculinity and college men's use of aggression and fighting.

\section{Masculinity on the College Campus}

Michael Kimmel has researched masculinity and college masculinity extensively in his book Guyland. The title comes from Kimmel's observation that college, or "guyland", is a culture dominated by men where boys are socialized into adult men (Kimmel, 2008). Part of this socialization process is explained through what Kimmel refers to as the "bro code" (Kimmel, 2008). The "bro code" is a tangible set of rules for college men which looks something like this: mad is better than sad; instead of getting mad, get even; and nice guys finish last (Kimmel, 2008). Because of this code, when college men are presented with a confrontational situation, they will likely express aggression physically as a way to prove their masculinity and adhere to the rules of college masculinity. Fighting allows men to prove that when they are faced with confrontation, they will get mad or even with the transgressor both as a form of retaliation and also as a way to prove masculinity. In Kimmel's (2008) exploration of college men's masculinity, he suggests that college men perform masculinity for other men. Often men employ the use of physical aggression as a way to constantly prove their masculinity. Kimmel suggests in Guyland that, "you can pretty much guarantee starting a fight virtually anywhere in America by questioning someone's manhood" (Kimmel, 2008: 100). Kimmel's point highlights the idea that men's use of physical aggression, specifically fighting, is a common characteristic of masculinity, especially for college men. In the United 
States, a fight is likely to occur when a man's gendered reputation is challenged. This means regardless of the situational context, for men, fighting is a key way to demonstrate hegemonic masculinity.

Similar to traditional masculine gender norms that provide boys and men with a blueprint for how to engage in appropriate masculine behavior, the "bro code" provides college men with a set of socially agreed upon rules for performing masculinity (Kimmel, 2008). Kimmel's "bro code" reinforces traditional masculine gender norms and supports the findings from previous studies on men who fight because Kimmel's work links college masculinity with aggression, violence, and fighting (Benson \& Archer, 2002; Campbell, 1993; Connell, 2000; Kimmel, 2008). As previously mentioned, Connell (2000) suggests that when men demonstrate aggressive behavior, they are "boys being boys." Similarly, Kimmel (2008) explains that men in college who engage in aggression and fighting are boys being socialized into men. Both of these concepts serve to justify men's use of physical aggression in a variety of social environments, including the college campus. When men fight to resolve conflict, their behavior is often justified based on existing masculine gender norms.

Men's use of physical aggression is an essential part of traditional masculine gender norms, and looks the same in a variety of social situations including the context of college masculinity. Although men may engage in aggressive behavior for trivial reasons, aggression and fighting are often ways for men to prove their masculinity and defend their gendered reputation (Campbell, 1993; Connell, 2000; Kimmel, 2008). This means that in a variety of social situations, when men perform 
masculinity they are likely to use physical aggression, and their behavior will likely be justified. This thesis builds upon previous studies on college masculinity because it further explores the way college students perceive fights in terms of college men building and defending their gendered reputation.

For the purpose of this thesis, I define gender and masculinity as social constructs that are being performed in all social situations (Butler, 1988; West \& Zimmerman, 1987). I rely on Connell's (2000) concept of hegemonic masculinity to further define masculinity as the most highly valued masculine behavior. In terms of traditional masculine gender norms, aggression, violence, and fighting represent highly valued masculine behavior, or hegemonic masculinity (Campbell, 1993; Connell, 2000). Previous studies on gender, masculinity, and fighting further emphasize the notion that fighting is a chief way for men to perform masculinity especially within the context of the college campus (Benson \& Archer, 2002; Brown \& Tappan, 2008; Campbell, 1993; Cobbina et al., 2010; Connell, 2000; Kimmel, 2008; Lowe et al., 2012). Now that a better understanding of the literature on men's use of aggression has been established, it is important to discuss femininity and how it relates, aggression, violence, and fighting. 


\section{Chapter 3: Femininities and Women's Aggression}

In the introduction I defined gender performance as repeated gendered behavior that individuals engage in during all social interactions (Butler, 1988). Because gender is part of all social interactions, it is important to understand the relationship between femininity, aggression, and violence. In order to understand these concepts, I will first define and explore the concepts of femininity and traditional feminine gender norms. Next I will examine literature on traditional feminine gender norms with a focus on women's use of aggression and violence. Then I will explore the way previous studies on femininity, aggression, and violence have influenced this thesis in terms of college femininity.

\section{Defining Femininity and Emphasized Femininity}

Just as gender and masculinity are culturally constructed, so is femininity. Femininity is a role performed based on cultural understandings of what it means to be a girl and woman. This working definition of femininity fits with the gender performance literature because it suggests that femininity is socially constructed and performed accordingly (Butler, 1988). For example, a defining characteristic of femininity is being passive and introverted, so women often perform femininity by being physically passive during confrontational social situations (Campbell, 1993; Jack, 1999). Building from the notion that femininity is a socially constructed gender performance, I rely on Connell's (2000) work on emphasized femininity to further conceptualize femininity. Emphasized femininity is an exaggeration of traditional feminine gender norms for girls and women where women are expected to be passive, fragile, and weak (Connell, 2000). This framework for understanding 
femininity is dualistic in that when women do not meet traditional feminine gender norms, their behavior is an alternative to emphasized femininity. Similar to hegemonic masculinity, this concept of emphasized femininity is pluralistic because there are different ways of "doing" femininity, including emphasized femininity and alternative femininity (Connell, 2000; West \& Zimmerman, 1987).

When women adhere to emphasized femininity, they are compliant in their own subordination because they exaggerate traditional notions that women are weak and inferior (Cobbina et al., 2010; Connell, 2000). The concept of emphasized femininity is critical to this thesis because I focus on fighting, a traditionally masculine behavior, so when women fight it serves to resist emphasized femininity. Women who fight emulate an alternative to emphasized femininity because traditional feminine gender norms for women dictate that in confrontational situations women should be physically passive (Campbell, 1993; Jack, 1999). Although there are other ways to conceptualize femininity such as a biological essentialism, it is important for this thesis to use a social constructionist approach because traditional feminine gender norms can vary cross-culturally. Emphasized femininity provides a complex framework for understanding femininity as a social construct where women who adhere to traditional gender norms represent emphasized femininity, and women who resist traditional feminine gender norms represent an alternative to emphasized femininity (Campbell, 1993; Connell, 2000; Jack, 1999). 
Emphasized femininity fits with the micro level analysis used in this thesis because in this framework, femininity is an integral part of all individual social interactions. In conjunction with hegemonic masculinity, emphasized femininity works to create a gender hierarchy where traditionally masculine behavior is at the top of the hierarchy and is dominant over traditional feminine behavior (Cobbina et al., 2010; Connell, 2000). For this thesis on fighting (a traditionally masculine behavior) and the way fights serve to build and defend college men and women's gendered reputation, it is important to understand that masculinities and femininities exist on a gender hierarchy. Gender is part of all social interactions (Butler, 1988), and these social interactions fall on the gender hierarchy depending on how masculinity and femininity is being appropriately performed. To better understand emphasized femininity and the alternative to emphasized femininity, a more in-depth exploration of traditional feminine gender norms for girls and women is necessary because traditional feminine gender norms define behavior as emphasized femininity or alternative behavior.

\section{Traditional Feminine Gender Norms and the Use of Physical Aggression}

Gender norms and expectations have traditionally limited the use of physical aggression for girls and women because of the myth that, “...men are naturally aggressive, [while] women are naturally unaggressive" (Jack, 1999: 18). Girls and women are socialized to express aggression differently than boys and men because boys are socialized to believe aggression as an issue of social dominance, while girls are socialized to believe that expressing aggression is a failure of personal control 
(Campbell, 1993). When these traditional gender norms persist, they remain pervasive in perceptions of social interactions. The resulting view is that men are expected to use physical aggression while women are not (Campbell, 1993). Based on traditional feminine gender norms, the expectation is that women should not use physical aggression. When faced with confrontational social situations, women traditionally are expected to practice restraint. When women do engage in physically aggressive behavior such as fighting, this behavior is often perceived as resisting traditional feminine gender norms, the defining feature of resisting emphasized femininity.

Connell's (2000) work on emphasized femininity is key to this thesis in that his work suggests that behavior such as fighting is alternative to emphasized femininity because fighting breaks traditional feminine gender norms. The emphasized femininity framework provides a system of femininities where a combination of compliance, resistance, and cooperation to traditional feminine gender norms (i.e. emphasized femininity) exists as women perform femininity (Butler, 1988; Connell, 2000). In confrontational social interactions fighting is one way for girls and women to protest emphasized femininity, and this resistance to emphasized femininity provides an alternative to traditional feminine gender norms. Having an alternative to emphasized femininity within the gender hierarchy suggests that when women break traditional feminine gender norms, they may not be perceived as deviant but rather they fit somewhere else on the gender hierarchy. In order to better understand the relationship between alternative emphasized 
femininity and aggression, it is crucial to further explore previous studies of women who engage in deviant behavior.

\section{Previous Studies: Emphasized Femininity, Aggression, and Fighting}

Previous literature suggests that when girls and women engage in behavior that deviates from traditional feminine gender norms, including but not limited to fighting, often they are designated into one of two categories: "mad or bad" (Belknap, 2007; Chesney-Lind, 1986; Gilbert, 2002). This notion that deviant women are "mad or bad" means that when women break traditional feminine gender norms, they are perceived and labeled as either crazy or deviant in order to mark them abnormal (Belknap, 2007; Chesney-Lind, 1986; Gilbert, 2002). For example, one study on gender and aggression explains "women who act aggressively are much more likely to be labeled as mentally ill" (Day et al., 2003). This notion that when women deviate from traditional feminine gender norms, they will be perceived negatively is not limited to women who fight. Women who engage in traditionally masculine professions such as the military also risk negative perceptions because their behavior is perceived as being deviant from traditional feminine gender norms. Additionally, being labeled deviant or crazy is not the only potentially negative consequence of resisting emphasized femininity. Often when women break traditional feminine gender norms, their behavior is perceived as inferior to men who perform the same behavior.

One study that explores women who resist emphasized femininity by employing a traditionally masculine profession suggests that when women and men 
perform the same professional duties (that of solider), women are evaluated as inferior compared to men (Boldry, Wood, \& Kashy, 2001). The findings from Boldry et al. suggest for women, gender norms negatively influence the perception of their peers and superiors during evaluations (Boldry et al., 2001). The findings from this study provide an example of one way in which women resist emphasized femininity because being in the military is an untraditional feminine profession. This study suggests that women in the military may not be labeled as "mad or bad" even though their profession breaks traditional feminine gender norms. However, traditional feminine gender norms still negatively influenced perceptions of women soldiers. A hierarchy of perceived behavior exists; when men and women behave similarly and perform the same tasks, women are often perceived and ranked lower than men of equal standing. As the Boldry et al. (2001) findings suggest, when men and women cadets fulfilled the same requirements for a particular military program, men were perceived as being more competent than women and were described as more motivated, diligent, and better leaders than women. In the Boldry et al. (2001) example of women in the military, when women break traditional feminine gender norms by having a masculine job, their behavior may not be labeled "mad or bad" because their non-traditional behavior serves a professional purpose. However, women's engagement in non-traditional behavior is still perceived as different and ranked lower than men performing the same behavior. The findings from Boldry et al. (2001) reflect the gender hierarchy.

While women who break traditional feminine gender norms and resist emphasized femininity risk negative perception and treatment by their peers, 
deviation from traditional feminine gender norms can also serve to benefit women in certain social situations. Day et al. (2003) found that in Britain, fighting was acceptable behavior for working-class women. The findings from Day et al. (2003) suggest that for working-class women fighting was a way to behave heroically, a way to navigate their reputation as being "hard" or tough, and fighting also provided disenfranchised women with some social advantages such as status (Day et al., 2003). These findings suggest that for working-class women, fighting can be positively perceived because of class-based social expectations. Working-class women do not always have to conform to traditional feminine gender norms the same way middle-class women do (Day et al., 2003). When working-class women deviate from traditional feminine gender norms, often they are not labeled mad or bad because their behavior is perceived as representative of their working-class background. Often, fights among working-class women are justified as part of their "tough" class-based identity.

Previous studies that explore women who fight have mostly focused on urban locations because this setting has traditionally been the focus for studies on violent crime (Brown \& Tappan, 2008; Chesney-Lind \& Jones, 2010; Ness, 2004). Similar to studies on working-class women who fight, Chesney-Lind and Jones' study (2010) on urban women who fight suggests that fighting can be used to create a tough image and as a tool for survival. According to the authors, "Girls know that the settings of inner-city life... do not come with a special girls-only pass to live beyond the reach of violence" (Chesney-Lind \& Jones, 2010: 7). This suggests that 
girls and women from urban locations often use violence as a way to navigate and survive in their everyday lives.

Even though traditional feminine gender norms suggest that girls and women should be passive social actors, survival in urban areas may require women to engage in more aggressive behavior (Campbell, 1993; Chesney-Lind \& Jones, 2010; Jack, 1999). In the context of urban women's use of physical aggression, masculine behavior such as fighting may not to be perceived as deviant because it serves as a way for women to navigate social situations and gain status. When girls and women from urban neighborhoods deviate from traditional feminine gender norms, their behavior resists emphasized femininity. However, they may not be labeled mad or bad because their behavior is perceived as representative of their social climate. Often, fights among urban girls and women are justified in part because of the social expectations associated with their urban environment.

In another study of urban women's use of aggression, Ness' ethnographic study in Philadelphia (2004) suggests that women from inner cities use physical aggression as a tool for survival and as a way to contribute to self-identity. Similar to Day et al., Ness (2004) found that when women in her study participated in fights, they were perceived as and self-identified as tough. This study also suggests, "violent behavior by male and female juveniles routinely continues to be assigned different causal factors" (Ness 2004: 32). Essentially, when girls and women from urban neighborhoods engage in physical violence, it serves a variety of functions, similar to boys and men. However, when men and women express similarly 
aggressive behaviors, their actions are still gendered and perceived differently by their peers. In Ness' (2004) study, fights between girls and women were often perceived as trivial, and fights between boys and men were often perceived as serious despite their behavior being described as similar.

There appear to be some similarities between findings for women who take on masculine roles through their choice of profession, such as being in the military, and women who need to rely on masculine behavior to emulate a "tough" persona and to serve as a form of survival in their social environment. In all of these situations, when women engage in masculine behavior either professionally or in confrontational situations, their behavior is similar to men's but perceived differently. Even though when women hold masculine professions or fight they break traditional feminine gender norms, given certain situations, women's use of aggression and violence is described and perceived as essential rather than crazy or deviant.

The findings on women in the military (Boldry et al., 2001), working-class women who fight (Day et al., 2003) and women from urban neighborhoods who fight (Brown \& Tappan, 2008; Chesney-Lind \& Jones, 2010; Ness, 2004) are similar in that they provide examples of alternatives to emphasized femininity. An alternative to emphasized femininity is often acute to survival for working-class and urban women, because their aggression and fighting is often perceived as important to their identity and to their survival. Although findings regarding perceptions of working-class and urban women's use of aggression and fighting cannot be 
generalized to college women, it is important to understand these previous studies as fights between college women are being normalized by students (Weiss, 2013). Previous studies that suggest working-class and urban women's use of aggression is important and justified rather than deviant may provide insight into the way college women's fighting is perceived (Brown \& Tappan, 2008; Chesney-Lind \& Jones, 2010; Day et al., 2003; Ness, 2004). To better understand how fighting influences a college woman's gendered reputation, I will now explore literature on college women's femininity.

\section{Femininity on the College Campus}

College women's use of physical aggression is often neglected in studies of gender and aggression because aggression is often framed as behavior that primarily impacts women from working-class backgrounds and urban areas. One study that touches on college women's use of physical aggression is Weiss' exploration of the party school (Weiss, 2013). Although this study primarily addresses broader issues related to schools with a party reputation (i.e. heavy binge drinking, property crime, and the normalization of crimes and victimization), it is important to note the contribution this study makes to research on women's use of aggression. In her exploration of the party school, Weiss (2013) found that fights with men and fights with women are commonplace in the context of the party subculture. Women casually discussed their involvement in fights on campus such as one respondent who described her experience participating in a fight that was a result of not receiving a ride home from a roommate. The college women explained 
the fight as something that “'just sorta happens"” (Weiss, 2013: 82). This description of a fight between two college women suggests that when college women fight, their behavior is normalized and labeled neither "mad nor bad."

Armstrong and Hamilton's (2013) five-year longitudinal study on college women and partying explores the role of gender in different pathways including the party pathway. In Paying for the Party Armstrong and Hamilton (2013) define the party pathway as a way to experience college rooted heavily in the Greek system and highlighted by heavy drinking and partying. Women in the party pathway must adhere to traditional feminine gender norms of passivity including introversion, niceness, and catering to the needs of others (Armstrong \& Hamilton, 2013). When women do not adhere to these traditional feminine gender norms, they risk being verbally insulted by peers with labels such as "slut" (Armstrong \& Hamilton, 2013). Often the women in this study used verbal insults such as "slut" to suggest that a woman did not meet feminine gender norms rather than to indicate promiscuity. These verbal insults were used as a way to attack a woman's gendered reputation (Armstrong \& Hamilton, 2013).

In Paying for the Party, Armstrong and Hamilton (2013) suggest that women actively participate in the party pathway, a culture comprised of risky behavior that is not associated with traditional femininity. Incidentally, the expectation is that women still adhere to traditional feminine gender norms embedded in being physically passive during confrontational social situations. Women must balance traditional feminine gender norms with the expectations of the party pathway or 
they risk verbal insults. Consequently, some aspects of the party pathway such as attending large and chaotic parties may oppose traditional feminine gender norms such as introversion. Despite what appears to be a conflict of social norms for college women, this study does not provide an exploration of the ways in which college women's participation in less traditional behavior contributes to their gendered reputation.

Although Armstrong and Hamilton's (2013) study does not directly address the way competing social norm expectations impact the lives of college women, the study does provide insight into the complex world of college women's femininity. Like Weiss' (2013) study of the party school, Armstrong and Hamilton (2013) establish that women normalize risky behavior associated with college parties. The authors explain, "the importance of the party scene for the production of fun, status, and belonging also meant that women tended to gloss over, or not take seriously, some of its other costs" (Armstrong and Hamilton, 2013: 92). Essentially, Armstrong and Hamilton's (2013) study suggests that as women participate in the party pathway they must simultaneously have fun, achieve high status, and find belonging while still maintaining a femininity comprised of traditional feminine gender norms. These expectations result in a hierarchy for college women where women at the top balance the party lifestyle, including the associated risky behavior, with traditional feminine gender norms (Armstrong \& Hamilton, 2013).

For women in the party pathway, which Armstrong and Hamilton (2013) suggest is a majority of students, ideal college femininity requires being "cute", 
having a good personality, and being sexy not slutty. In the context of the party pathway being "cute" means having designer clothes and wearing the latest fashion trends. Having a good personality means women at the top of the college femininity hierarchy, especially sorority women, have common interests. Usually women are perceived as slutty rather than sexy if their clothing is inappropriately revealing for a particular social situation, if they earn a reputation for being promiscuous, or if they behave socially inappropriately (i.e. different than their peers), especially at parties. It is clear from the women in Paying for the Party (2013) that in many ways college women must adhere to traditional feminine gender norms. While the book does focus on the ways in which the Greek system and sororities provide a way for women to attain these marks of college femininity, the book does not elaborate on ways in which women defend their femininity when it is under attack (Armstrong \& Hamilton, 2013).

The relationship between the use of physical aggression, traditional gender norms, masculinity, and femininity is a continuum. On one end of the spectrum there is masculinity, which is highlighted by dominance in social situations and fighting during confrontations (Campbell, 1993; Connell, 2000; Greig, 2000). On the other end is femininity, highlighted by introversion in social situations and physical passivity during confrontations (Campbell, 1993; Connell, 2000; Jack, 1999). All social interactions are a performance of gender norms, and it is difficult to divorce gender norms from perceptions of social interactions (Butler, 1988). These ways of thinking of gender and the use of physical aggression are important to understanding gender and fighting on college campuses because previous studies of 
college students suggest that in many ways traditional gender norms continue to exist on campuses (Armstrong and Hamilton, 2013; Kimmel, 2008). Additionally, previous literature suggests fights between college men and women occur and are often normalized (Weiss, 2013). To further explore the way college students perceive fighting and building and defending a gendered reputation as an explanation for why men and women fight, this thesis employs a qualitative approach to be discussed in the following chapter. 


\section{Chapter 4: Research Objectives and Methods}

\section{Objectives}

The objectives of this thesis are to expand upon previous studies that evaluate college masculinity, college femininity, the college party subculture, and the associated risky behavior. I will explore these concepts using focus group interviews conducted with college students about their perceptions of fights between their peers. Specifically, this thesis explores the research question:

How is building and defending a gendered reputation perceived by college students as an important reason for explaining why college men and women fight?

Studies that explore partying in the context of the college campus focus broadly on a variety of risky behaviors that are normalized by students (Weiss, 2013). While this research does provide some insight into fights that occur on college campuses, previous studies do not focus exclusively on the way gender norms influence perceptions of fights. Though many studies have explored perceptions of why young people fight and the gender of fight participants, these studies have focused primarily on urban environments and the explanations given by the fight participants (Brown \& Tappan, 2008; Chesney-Lind \& Jones, 2010; Ness, 2004).

This thesis is unique in that it explores gender and fighting in the context of the college campus, and this study also focuses on the explanations provided by witnesses of fights rather than fight participants. The current study explains how college students perceive fighting as a way for college men and women to build and 
defend their gendered reputation. This thesis will provide insight into how college students rely on gender norms to perceive and describe fights they have witnessed and heard about. Additionally, this thesis will show how students use gender to process why fights occur in terms of the gendered reputation of fight participants.

\section{Methods}

This thesis uses focus group data and applies an inductive, grounded theory. Focus groups are interviews in which a moderator leads a discussion regarding the specific themes of the research (Kvale \& Brinkmann, 2000: 324). This thesis uses an inductive, grounded theory in that I started by interviewing students and asking them questions about their perceptions of fights they had witnessed and heard about. I applied grounded theory by looking for themes that explained students' perceptions of how fights build and defend gendered reputation based on the gender of fight participants. By coding for explanatory themes, I focused on the ways college students perceive building and defending a gendered reputation as an important reason for explaining why college men and women fight because this was integral and recurring throughout the focus groups. Focus group participants explained that there were a variety of reasons why college men and women participated in fights in terms of their gendered reputation, and these reasons were often perceived differently based on the gender of the fight participants.

In this project, I seek to explore gender norms and their influence on students' perception of fights in terms of 1) the gendered reputation of college men who fight; and 2) the gendered reputation of college women who fight. The current 
study is exploratory in that few previous studies have focused exclusively on gender and college fights. Focus groups are the most appropriate form of data collection in that they provide researchers with a way to measure a variety of opinions on exploratory topics (Krueger \& Casey, 2009: 2). Additionally, my thesis is fueled by exploratory, open-ended questions that deal with perception so focus groups are an ideal fit because they provide insight into patterns and themes that occur organically in group discussions (Kvale \& Brinkmann, 2009: 324).

When researchers collect data on the college campus, one-on-one interviews and surveys are often popular. Although these two forms of data collection were available for the current study, one-on-one interviews only provide insight into individual perspectives rather than a variety of opinions within one discussion. Survey data offers more representative results, but when collecting data on questions related to perception, using survey data can be challenging because it can restrict data if the responses are not exhaustive. When research projects that focus on perception rely exclusively on one-on-one interviews or surveys, they run the risk of obtaining data that lack variety and saturation (Kruger \& Casey, 2009). In studies where measuring perception is central, focus groups are often the best option because they allow participants to explore and share ideas, yet they do not have to be in agreement (Krueger \& Casey, 2009). Focus groups are also beneficial because they allow researchers to evaluate and analyze perceptions of a particular topic without the clinical feel of one-on-one interviews (Krueger \& Casey, 2009; Kvale \& Brinkmann, 2009). Ultimately, I decided to use focus groups as the source of data for my thesis because my research question concentrates on perception. 
Typically, there are five key components to focus group interviews. According to Kruger and Casey (2009), focus groups should have "(1) people, (2) who possess certain characteristics, (3) provide qualitative data, (4) in a focused discussion, (5) to help understand a topic of interest" (Kruger \& Casey, 2009: 6). For this thesis, the desired sample is undergraduate students at a large university with a significant partying reputation. Although I sought participants who felt they had adequate knowledge of fights, I did not require focus group members to have witnessed or participated in a fight in order to participate in the focus group interviews. Other types of data collection offer some of these characteristics outlined by Kruger and Casey, but focus groups are unique in that you have multiple participants with similar characteristics providing a variety of perspectives (Kruger \& Casey, 2009; Morgan, 1997). Focus groups provide substantive insight and variety into the perceptions of a particular group of people.

\section{Sampling}

I collected data from a large North Central university from December 2013 to February 2014. My total sample size was 14 students. Initially I recruited participants exclusively from Women and Gender Studies classes. While this sample was primarily obtained through convenience sampling, such a sampling method is appropriate given that this project is exploratory and may not speak to the entire undergraduate population. Once I started collecting data, I also employed snowball sampling by asking participants from the first focus groups if they had friends who would be interested in contributing to future research. This sampling method 
provided me with participants who felt confident in their ability to discuss fights on campus. My sampling frame for the focus group was the entire undergraduate population of 30,000 students for the 2013-2014 school year. Because a snowball sample was employed for the second and third focus groups, my final sample may adequately represent the broader undergraduate population given that recruited participants had a wide range of backgrounds.

I conducted a total of three focus groups, each comprised of four to five participants $(\mathrm{N}=14)$. Typically, focus groups have between five and ten people with ten being the ideal number. However, focus groups can have as few as four and as many as twelve participants (Krueger \& Casey, 2009; Kvale \& Brinkmann, 2009; Morgan, 1997). Ten is usually the ideal number because having focus groups that are too small can result in being less productive, especially if participants are unfamiliar with the topic. Meanwhile, having larger focus groups can result in the facilitator having difficulty managing the discussion (Morgan, 1997). When deciding on the number of participants for a specific focus group, it is important to keep the number small enough so that no voice is silenced while also providing a variety of perspectives (Krueger \& Casey, 2009).

For the purpose of the current study, I was concerned with keeping the focus group sessions to around an hour. I wanted to ensure that participants remained interested and focused. I was worried that if the focus groups were too long, participants would lose interest. The focus group sessions ranged in length from an 
hour to an hour and 20 minutes. Having four to five participants per interview and keeping the conversation close to an hour helped keep the conversation rich in data.

Because I used convenience and snowball sampling methods, it is important to compare my sample with the undergraduate population of the university. In terms of gender the sample was fairly representative although there were slightly more men. The sample was $57 \%$ men $(\mathrm{N}=8)$ and $43 \%$ women $(\mathrm{N}=6)$ while the university's population was 54\% men and 46\% women ("College Portrait", 2013). The average age of participants was fairly representative of the undergraduate population. The age of participants ranged from 18-22 with a mean age of 19 . The mean age of the undergraduate population was 21 ("College Portrait", 2013). Because I over sampled in lower-level classes, it makes sense that the mean age for the sample was slightly lower than the mean age of the population.

The last important demographic characteristic to consider when comparing the population and the sample is race and ethnicity. The sample was $79 \%(\mathrm{~N}=11)$ white and $21 \%(\mathrm{~N}=3)$ black. The university's undergraduate population was $83 \%$ white, $4 \%$ black, and 13\% other minorities ("College Portrait", 2013). While the sample does provide some diversity, it over represents black students and lacks representation from a variety of minority groups. Future research should provide more representative data, especially in terms of race and ethnicity. This will provide more accurate insight into the perceptions of all college students. 


\section{Procedure}

I recruited focus group participants at a large land grant university with an Internal Review Board approved recruitment script (Weiss, 2013). The script was read at the end of seven classes, and I waited a few minutes after each class ended in case students wanted to ask further questions. If students were interested, I answered any questions and then exchanged email addresses so that we could communicate and finalize the location, day, and time of the focus group. Once I found a sufficient number of interested students, I sent an email to all prospective participants. The email included possible days and times and directions to the Women and Gender Studies office. I also attached the recruitment script.

I conducted three focus groups at the Women's and Gender Studies office, and each interview was recorded using a tape recorder. Because each focus group took place in the evening after faculty and staff had finished their workday, I conducted the focus groups in a lobby area with couches and a television rather than a formal setting such as a conference room. I chose this location because more relaxed environments tend to make participants feel more comfortable. This often allows respondents to speak more openly and candidly about their experiences.

Once all participants arrived at the office, I briefly summarized the project, explained that the interview would be recorded, and asked if they felt comfortable being recorded. I also reminded students that although I would keep their responses confidential, other participants could discuss the data after the focus group. After participants agreed to be recorded, I asked them to fill out a brief demographic 
survey. As they completed the survey, I gave the participants a sticky note with an assigned number. For the rest of the interview, I only referred to participants by their number in order to protect their identities. Once the demographic surveys were completed and each participant was assigned a number, the interview process began.

First, I ensured that all focus group participants were conceptualizing fights the same way. I established that conversation should center on fights and defined fights as a physical altercation without a clear victim or offender that occur on or near their campus (Weiss, 2013). Then I asked participants to think about fights on campus that they had observed or heard about while in college. I organized my questions into two sections: 1) one-on-one fights between two college men; and 2) one-on-one fights between two college women. Each section started with descriptive questions about the location, length, and type of contact for a typical fight. After participants established what a typical college fight looks like, I asked questions about perception such as how entertaining and commonplace they viewed fights (see appendix A for the interview protocol). Although I used a general protocol to navigate the interviews, focus groups are unique in that students are able to bounce ideas off each other. Sometimes the conversation deviated from the protocol, but such divergence was always driven by participant input.

Once I felt that all of the questions from the protocol had been addressed, I asked participants if they had any final ideas they wished to discuss related to gender and fighting. By asking participants for their final thoughts, I aimed to ensure 
that I did not overlook any relevant topics. This last question also provided participants with the opportunity to address any topics that were sensitive in nature or that they felt needed further exploration. Ending with an open-ended question was important given the sometimes violent content of the conversation and to ensure that no voice went unheard. After participants felt they had no other contributions to the topic of gender and fighting, I thanked participants and ended the recording.

If participants needed to further discuss the material covered in the focus groups, I stayed in my office afterward so that they could informally discuss the topics we had covered. Participants from both the first and third focus groups opted to stay. The participants who stayed explained that the interview was challenging because the topic of fighting was relevant to them on a personal level. I answered questions about the project and provided more details about my research. After each focus group, the recording was transcribed using the application "Speedible." This application allows researchers to easily slow down and stop the recording while transcribing. There were 125 single-spaced pages of transcripts.

\section{Coding}

Once all of the data were collected and transcribed, I printed and read through the transcripts. I highlighted and color-coded important passages and took notes. Because gender is central to this thesis, I looked for keywords such as masculine and feminine. After I evaluated the data from all three transcripts, I looked for recurring themes and patterns. Based on my review of literature, my 
research question, and my focus group protocol, I decided to organize data into two sections based on student perceptions of gender. Initially, I looked for data on 1) the role fights play in college men's gendered reputation; and 2) the role fights play in college women's gendered reputation. I organized the data into sections based on gender because perceptions of gender are the foundation for this thesis.

As distinct patterns and themes began to emerge, I began to further organize the data within the original two sections (men's fights and women's fights). For men, I organized data based on the following recurring themes: fighting to prove masculinity, making a need for fights, fighting to perform masculinity, and the consequences of losing a fight and showing emotion. For women, I organized data based on the following recurring themes: defending a gendered reputation against verbal insults, seeking validation from friends, needing to explain why they fight, and taking pride in fights. I copied and pasted passages from the transcripts into the corresponding word documents for each theme. This system allowed me to organize quotations from different focus groups into cohesive themes. Combining data from different focus groups based on these themes allowed me to better understand the similarities and differences in perceptions that students had in terms of gender and fighting.

When I organized data that related to the focus group members' perception of college men and women who fight and their gendered reputation, I looked for key words such as "masculine", "feminine", "reputation", and "ego." These keywords were important because they indicated a discussion of traditional gender norms 
that were influential in terms of fighting and reputation. I also looked for passages where study participants used words such as "proving something" and "shame" as these words were often discussed in relation to fight participants building and defending their gendered reputation. Additionally, when participants discussed the events of a fight, this often led to a discussion of the way participating in a fight influenced an individual's reputation. Finally, I paid close attention to areas of conversation that detailed perceived motivation and perceived post fight events because often focus group participants made a connection between motivation and reputation as well as fight outcome and reputation.

The method for the current study is qualitative in nature and may not speak to the entire university population or other similar universities where heavy partying occurs. When studies that employ focus groups are generalized to a larger population, this can lead to biases because interpreting data with a small sample size limits the findings to the experiences of a few (Morgan, 1997). Rather these three focus groups are meant to provide insight into specific examples of fights and the way gender norms influence the perception of college students in terms of the gendered reputation of fight participants.

This thesis is limited for a variety of reasons. The population and sample lack diversity, the sample may not be generalizable to all party schools given the small sample size, and this study neglects schools that are not party schools such as commuter schools and community colleges. Future studies that explore perceptions of gender and fighting should explore topics related to race and ethnicity, class, and 
other aspects of identity on a variety of college campuses. Because this thesis lacks diversity, has an unrepresentative sample, and because the sample size was small, the findings from this thesis may not be generalizable to all colleges with similar party subcultures. However, because it appears that participants in the current study had similar experiences to students of previous studies that focus on colleges with party subcultures, the results can speak to some aspects of the experiences of students at schools with distinct party subcultures.

Data for this thesis was collected at a university notorious for its drinking culture. While drinking, partying, and fighting may occur on a variety of college campuses, future studies should include the experiences of students who attend campuses with a different, less party-oriented climate. Students from different types of colleges (i.e. commuter schools and community colleges) may have different experiences and perceptions of gender, fighting, and reputation. The current study also focuses exclusively on one aspect of why college men and women fight and does not explore a variety of ways in which the gender of fight participant's influences students' perceived explanations for fights. Future studies should explore party schools with more diversity and schools that are not known for their party subcultures. Future studies should also look at a variety of reasons for why students participate in fights in relation to the gender of fight participants such as the more trivial explanations provided in previous studies (i.e. a spilled drink or a wrong look). 
All data for this thesis are presented with relevant information including the age and sex of the respondent. The identities of focus group participants remain protected; but because this thesis focuses on the topic of gender, it is important for readers to know the sex of the speaker. Additionally, knowing the age of the speaker is also important because it helps contextualize the experiences of the respondents. For example, when focus group participants say they have experienced few fights, it is important to know if this is because they do not attend many parties or because they are freshmen and data was collected during their first or second semester. It is also important to note that all bracketed dialogue indicates that the interviewer and not a focus group participant is speaking. Now that I have explained the data collection process, I will further explore the two sections that drive this thesis: perceptions of fights between college men and perceptions of fights between college women. As I explore the way fighting is perceived as contributing to college men and women's gendered reputation, I will present data that relates to my research question and connect the current findings to previous literature. I will also provide suggestions for future research. 


\section{Chapter 5: Findings -Fighting and Men's Gendered Reputation}

As established in the chapter on masculinities and aggression, men fight for a variety of reasons such as having a drink spilled on them, having someone look at them wrong, or to prove their masculinity (Benson \& Archer, 2002; Kimmel, 2008). While there is a wide array of explanations for why men fight, this thesis focuses on how building and defending a gendered reputation is perceived by college students as an important reason for explaining why college men and women fight. It is critical to understand the relationship between fighting and gendered reputation as an explanation for college fights because previous literature that examines gender and fighting suggests that building reputation is a key reason why young people fight (Benson \& Archer, 2002; Brown \& Tappan, 2008; Cobbina et al., 2010; Day et al., 2003; Kimmel, 2008; Ness, 2004). Similar to previous studies, throughout the focus groups, participants explained that they believed building and defending a gendered reputation was one of the most important reasons why college men fight.

Fighting for a gendered reputation is a complex explanation for why college students fight and deserves further elaboration. According to focus group participants, in terms of building and defending a gendered reputation college men often fight to prove their masculinity. Additionally, college men often make a need for a fight and fight to perform gender for the benefit of their peers. Although fights between college men often served as a way to build and defend their gendered reputation, often when college men show emotion during a fight, especially when 
they lose, their participation is perceived negatively in terms of their gendered reputation.

\section{Proving Masculinity}

As discussed in the second chapter on masculinities and men's aggression, aggressive behavior such as fighting is closely linked to masculinity (Campbell, 1993; Connell, 2000). Similar to traditional masculine gender norms, Kimmel's (2008) work in Guyland provides a foundation for college men's masculinity. Kimmel describes a variety of ways in which aggression is linked to college masculinity in what he refers to as the "bro code" (Kimmel, 2008). This code of college masculinity dictates that college men should prove their masculinity through aggression, perform masculinity for other men, and not show emotion (Kimmel, 2008). Kimmel's (2008) findings on college masculinity are reflected in responses from focus group participants in the current study in that both studies suggest fighting is a vital way for college men to prove their masculinity. For example, in one focus group the following conversation occurred when a focus group participant was asked why college men fight:

"... If it's that important for them to be fighting about it, let them fight it out and see. After the fight let them see, was it really that important for you to lose the fight, or to lose a tooth, or get a black eye?" -Male, 18

[What do you think would make that fight important then?] ${ }^{3}$

${ }^{3}$ All facilitator dialogue appears in brackets. 
"I mean probably disrespect. Disrespect or something like disrespect, treating them negatively. There's a lot of good enough reasons, and they still [are] gonna have petty reasons to it." -Male, 18

[So, you said you're gonna let them fight it out, you're not gonna tell on them, tell a police officer or try and get someone to break it up?]

"If it's in the club, I'm not gonna let it ruin my day." -Male, 18

[So as long as it's not ruining your good time, you're okay with it?]

"I mean if you're in the club, there's people around, it's not that big of a space regardless and there's a lot of people in there. So you might punch once. ...If it's that serious, take it outside. Be men about it. If ya'll are gonna fight about it, take it outside." -Male, 18

The speaker in this conversation indicates that if a college man feels disrespected, this is a legitimate reason to participate in a fight. The speaker believes that when two college men fight for "good enough reasons" and they throw punches, they need to "be men about it." If the fight meets his qualifications of a fight (i.e. punches are thrown and it is serious enough to be taken outside), the fight participants demonstrate their masculinity. The fight participants in the proposed scenario follow Kimmel's (2008) "bro code" in that their fight prove their masculinity because they are "being men about it." Similar to Kimmel's explanation in Guyland (2008) which suggests that fights serve to defend challenges to a college man's masculinity, the above data suggest that when college men are disrespected, fighting 
is one way to build and defend their gendered reputation by proving their masculinity (Kimmel, 2008).

The following passage further supports this finding that for college men fighting is often an important way to prove masculinity and build and defend a gendered reputation. In this conversation focus group participants discussed the positive relationship between fighting and a college man's reputation. The conversation from the next passage was sparked in response to the question, "what causes a fight?" It is important to note that the question that sparked this conversation did not relate to gender or reputation but rather a more general question about causation:

"Status, maybe attaining status within a frat or a little community." -Male, 18

"I think there's a lot of ego that goes with it." -Female, 18

"From what I've seen and all the fights I've heard, it really did sound like a combination of, it's complex but masculinity, men, they need to show that they're men, a lot of these people, again are frats with frats known as being hyper masculine." -Male, 19

Similarly, in another focus group a participant explained:

"I witnessed a fight where there was basically an arena inside the living room and two guys, they didn't have any altercation at all, it was just they wanted to beat each other up and see who was the better guy. And it went until blood was drawn and then they went their separate ways. They had no hard feelings for each other, it was, they just wanted to assert their masculinity."Male, 19 
These quotations demonstrate that focus group participants believed for college men, an important explanation for participating in a fight is their gendered reputation because fighting is a way to prove their masculinity. When focus group participants were asked to explain broadly why college men fight, the topic of masculinity and reputation was always on the forefront of conversation. This reaffirms the notion and perception that for college men, fights often serve to build and defend their gendered reputation. Not only do college men fight to prove their masculinity, focus group participants explained that often, college men make a need for a fight as a way to prove their masculinity.

\section{“Making a Need" for Fights}

According to traditional masculine gender norms, aggressive and violent behavior is excused with phrases such as they are just "boys being boys" (Connell, 2000). Traditional masculine gender norms serve to justify men's aggression, and men are expected to display aggressive characteristic traits by being dominant in social situations (Campbell, 1993; Connell, 2000). Literature on college men's masculinity parallels traditional masculine gender norms in that college men are supposed to act tough and prove their masculinity through the use of aggressive behavior (Kimmel, 2008). It is clear from previous literature on college masculinity that fighting is one way for college men to prove their masculinity because it is socially appropriate aggressive behavior. Fighting is an integral part of masculinity, and focus group participants believed college men often make a need for a fight as a way to prove their masculinity and build and defend their gendered reputation. 
During the focus groups I asked participants if fighting contributed to a college man's self-identity. In all of the focus groups, participants agreed that fighting was important to a college man's self-identity, and one way he could build and defend his gendered reputation. Many focus group participants believed that because college men need to prove their masculinity, they would make a need for a fight. The following conversation supports the notion that for college men, fighting often contributes to their gendered reputation, so they often make a need for fighting:

[For men, does participating in fights contribute to his self-identity, as a man?]

"It [fighting] makes him kind of seem like a tough guy like, 'I can take care of myself.' Even if there really wasn't a need for it anyway, it's like you make a need for it. So you can show this about yourself. I'm aggressive, I'm an aggressive man." -Male, 19

\begin{abstract}
"What I wanted to point out was my roommate, actually her boyfriend, so he walked into class...and he's half black and someone made a racial slur and he's not a very violent person, never been in a fight, but he went up to the kid and just straight decked him. She asked, you know, 'why'd you do that for? You're not a violent person, that's so out of character for you.' He said, 'you know I had to prove a point. I didn't want everyone in that class to think that it was okay, I didn't want him to think it was okay, I didn't want him to think I wasn't gonna stand up for myself.' That was his whole premise behind it." Female, 18
\end{abstract}

[Do you think that translates to other fights where maybe it's not sparked by a racial comment, but maybe that to stand up for yourself is important, to prove yourself so people won't mess with you again in the future?] 
“Yeah, and I think that's what he wanted, he didn't want anyone else to think that was acceptable to do. Not for anyone to make a racial slur about him but to pick on him in general." Female, 18

"A lot of times for me when it comes to fighting and building your identity, a crucial part of your identity is story telling or telling people stories. Like your friend's like 'oh hey this is what happened to me last weekend.' It sort of builds your character and people sort of know stuff based on the way you tell your stories and if you talk about being in fights or winning fights or if you're known for being a guy that gets into fights, it does build up a certain image of yourself. Some people might interpret this as bad, but in a lot of ways in the context of hyper masculine men, if you're known as a guy that wins fights, like my roommate's been in five or six fights now, ...he's won every one and he's known as, in the frat he's known as the super cool guy and 'oh he's a fighter, and he's really big and tough.' When you tell your stories of fights it definitely, the story moment kind of helps define who you are." -Male, 19

[It's [fighting] building your reputation and also it seems as though people tell their stories to sort of glorify their fighting?]

"It justifies it 'cuz if it's post fight and you can talk about it and you can put a positive spin on your fight and be like, 'oh it made my weekend so crazy' you know or it takes something that's sort of serious and can be deadly but make it kind of a fun thing that just happened in my life like it kind of... sugarcoats it in a way, but also just kind of makes it just an acceptable thing." -Male, 19

"I agree." -Female, 18

This conversation suggests that college men may make a need for a fight specifically so they can prove their masculinity, and so that other men will not challenge them in the future. When college men make a need for a fight, they can then tell the story of 
this fight. Story-telling becomes part of making a need for fights because once a college man makes a need and participates in a fight, he can tell the story of the fight to build and defend his gendered reputation. Story-telling also helps glorify fights between college men. When the story of a fight between two college men spreads on campus, they gain the reputation of being good fighters, something associated with masculinity. This passage also reaffirms that when college men fight, it is a way to build and defend their gendered reputation because it makes them seem "tough." When a man's reputation is challenged (in this situation because of a racial slur), fighting is one way college men can defend their gendered reputation and protect it for the future. In addition to making a need for a fight in order to prove their masculinity, college men's fights were also perceived as a way for men to perform masculinity for other men.

\section{Performing Masculinity: The Importance of Audience}

Micro level theories on gender suggest that not only is gender a part of all social interactions, gendered behavior is also performed for others and assessed by society (Butler, 1988; West \& Zimmerman, 1987). Similarly, Kimmel suggests in (2008) Guyland that college men follow the "bro code" to perform masculinity for other men. This thesis further supports findings that for college men, gender and masculinity are performed for others. Focus group participants explained that fights between men on campus often escalate when an audience is present because the fight participants fight to perform masculinity for their peers: 
"...With the frat and groups that are used to being in constant fighting, it seems like they can go out to the club, have a fight, go back to another club, rage some more, maybe get into another fight, then go home and the fight doesn't ruin their night 'cuz I guess they're just so use to it. Again my roommate that's in a well-known frat will get into two, three fights a night and just have a great night and it doesn't ruin it." -Male, 19

"And audience makes such a difference. Even a passive audience member, somebody's who's just there quiet, you know, just watching. Imagine, take away the audience you know..." -Male, 18

“No one's gonna fight if no one's around." -Female, 20

"It'd be more of a screaming match, you know, emasculate the other person verbally maybe that would be it. In certain situations I'm sure there'd still be a fight... If anyone's watching, it's a performance like getting up and singing. You fuel off of other people watching." -Male, 18

The speakers in the above conversation echo the findings of previous studies in that they believe some fights between college men would never escalate beyond a "screaming match" if the fight participants did not perceive fighting as a gender performance (Butler, 1988). These data also reaffirm the findings from Weiss' (2013) study of the college party subculture in that college students in both studies normalized the risky behavior of fighting. Focus group participants explained in the above passage that after college fights occur, often both participants and witnesses continued to party. Both fight participants and witnesses are unfazed by fights because this behavior is perceived as normal. Focus group participants linked college men's masculinity to fighting and building and defending a gendered reputation in a variety of circumstances. When college men fight to prove 
masculinity, make a need for a fight, and fight to perform gender their behavior is perceived as building and defending their gendered reputation. However, there were some situations where fighting could damage a college man's gendered reputation, such as losing a fight or showing emotion.

\section{Losing a Fight}

The previous data suggest that for college men, participating in fights is a way to build and defend their gendered reputation. Incidentally, focus group participants explained that gendered reputations could be damaged when college men lose a fight. To successfully build and defend a gendered reputation, college men must win the fight. If a college man loses a fight, he risks the perception of being weak and also runs the risk of showing emotion, which breaks Kimmel's "bro code" (Kimmel, 2008). For example, when discussing the relationship between a college man's self-identity and fighting, one focus group participant claimed:

"Yeah, I think if you're connected to thinking you're a big tough caveman then yeah it [fighting] would've. Like you said, it's connected to masculinity, you need to be manly. I bet if you lose a fight, I bet that would really hurt emotionally."-Male, 19

This quotation is complex because it indicates that losing a fight can have a negative influence on a college man's gendered reputation in that he risks the vulnerability of being emotional. This finding also suggests that when college men lose a fight, they risk being perceived as weak because showing emotion is not a traditional masculine gender norm. This finding speaks to previous literature on college men's masculinity because part of Kimmel's “'bro code"” is not crying and not showing 
emotion (Kimmel, 2008). For college men, losing a fight and getting emotional are often emasculating, and these are two ways to damage rather than build or defend a gendered reputation.

When college men fight, often their behavior is perceived by their peers as a way to build and defend their gendered reputation. When college men fight to prove their masculinity, to make a need for a fight, or to perform masculinity for other men, often their behavior is perceived as building and defending their gendered reputation. The findings from this thesis echo Kimmel's (2008) findings in Guyland, in that both studies emphasize the importance of college masculinity, aggression, and gendered reputation. While fighting often serves to build and defend a college man's gendered reputation, when he loses a fight or shows emotion, he risks damaging his gendered reputation because losing a fight breaks traditional masculine gender norms.

There are many reasons that serve to explain why college men fight, but focus group participants perceived building and defending a gendered reputation as an important explanation. The findings from this chapter support previous studies on college masculinity and also reaffirm traditional masculine gender norms that men should be aggressive during confrontational situations (Campbell, 1993; Connell, 2000; Kimmel, 2008). Now that a framework has been established for understanding college students' perceptions of gendered reputation and fights between college men, it is important to examine their perceptions of fights between college women. 


\section{Chapter 6: Findings -Fighting and Women's Gendered Reputation}

Traditional feminine gender norms indicate that when women are faced with confrontational situations, they should be physically passive (Campbell, 1993). Despite these parameters for women's use of physical aggression, just as college men fight for a variety of reasons, the same is true of college women. When college women fight, one explanation for this behavior is that it serves to build and defend their gendered reputations. The findings in this chapter will explore the way focus group participants' perceived fights between college women, and how building and defending a gendered reputation was believed to be an important reason for explaining why college women fight. The findings in this chapter will explore four circumstances when focus group participants believed that fighting served as a way for college women to build and defend their gendered reputation. The data for this thesis suggest that when college women fight because their opponent verbally insulted them, they have encouragement and validation from friends, they can explain why they fight afterward, or they take pride in fighting, their behavior is perceived as building and defending their gendered reputation. Rather than label all college women who fight as deviant, when their fights fell into one of the four circumstances, fights between college women were perceived as building and defending their gendered reputation.

Although fights between college women were often perceived as building and defending their gendered reputation, occasionally responses echoed traditional 
feminine gender norms. For example, one focus group participant believed that college women rarely, if ever, fight because they are innately peaceful and passive:

"It's more of a womanly nature to want to settle things. It's been proven that women are often the first ones to want to apologize first. We just want things to be settled, we just want, you know, this doesn't need to happen." -female, 18

This quotation reflects traditional gender norms and indicates that the speaker believed that college women should not fight, and when they do they go "against nature" and break traditional gender norms. While this focus group response mirrors traditional rhetoric, this outlook was isolated and not thematic. Recurring themes in the data suggest that many focus group participants perceived that building and defending a gendered reputation was an important explanation for why college women fight. The following section focuses on the role of verbal insults in terms of college women fighting to build and defend their gendered reputation.

\section{The Role of Verbal Insults}

As indicated in the chapter on femininities and women's aggression, previous studies suggest that when college women do not adhere to traditional gender norms, they risk verbal insults from their peers (Armstrong \& Hamilton, 2013). According to Paying for the Party insults such as "slut" were often used to attack a college woman's femininity rather than to mark her promiscuity (Armstrong \& Hamilton, 2013). Although Armstrong and Hamilton (2013) suggest that when college women break traditional gender norms they risk verbal insults from their peers, these authors do not address fighting in their study. Focus group participants 
in the current study also discussed the role of verbal insults such as "slut" and "trashy." However, they discussed the role of these insults in terms of college women's fights and gendered reputation.

When college women fight and their gendered reputation is already under verbal attack, fighting may serve to build and defend their gendered reputation. The findings regarding the role of verbal insults also suggest that when college women exchange insults via social media their behavior is more likely to be perceived as building and defending their gendered reputation. Additionally, when college women exchange verbal insults for a prolonged period of time prior to a fight, often the insults are perceived as more significant in terms of building a gendered reputation. Furthermore, the findings from this thesis suggest that when fights between college women are perceived as the result of verbal insults directed at a woman's physical appearance, the fight is more likely to be perceived as building and defending a gendered reputation. One focus group had the following conversation:

"I feel like sorority girls do get into fights because there's still that aspect of competition, but I feel like there's more rules, there are a lot of behavioral rules for women in sororities as far as if you do this you'll be in trouble. Whereas when in a frat it [fighting] might be rewarded." -Female, 18

"Whereas the sororities, you're bringing shame to the sorority 'cuz girls who fight are quote unquote considered 'trashy' in a lot of people's eyes. Whereas with guys it's just kind of a norm." -Female, 18

In another passage focus group participants explained: 
"If a girl knows that a guy she's involved with is sleeping around with another girl or something, I feel like she's gonna make that decision of 'oh she's gonna jump her' or there's gonna be a [verbal] fight prior to that actual fight." -Female, 18

"I think it starts on social media, like on Facebook like 'hey oh you're such a tramp' and then, you know it just escalates." -Male, 19

"I mean the words that are used are different too." -Male, 18

“...There's such a huge pressure to look physically perfect, and so once you threatened somebody's physical being I feel like, you know, once you're offended like 'oh she called my nose big' or whatever..." -Male, 19

"Coming back to that, girls will be the first one to be like 'oh you're fat.' How you said whenever men fight they try and emasculate the other one, I agree with that, women slut-shame like 'oh you whore.' (Other participants agree). They'll [women] be the first to attack a woman's sexuality... Even if they're not a slut." (Uncomfortable laughter from participants). -Female, 18

[You all mentioned that the fights between women might start through social media, is that something only happening between two women fighting or do you think that men might also...?]

"Nooo!" -Male, 19

"I mean it can happen with men..." -Male, 18

[Would you say that you think fights between women are more likely to be related to social media stuff compared to fights with men?] 
"Mhm, I would go that far." -Female, 18

These passages support the notion that despite the risk of further damage to her gendered reputation, if a college woman believes her reputation is under attack because of verbal insults, she can build and defend her gendered reputation by fighting. Additionally, these passages emphasize the critical role of social media, the importance of prolonged verbal insults, and the significance of insults related to physical appearance in terms of college women fighting to build and defend their gendered reputation.

In these passages, focus group participants explained that social media was central to college women's fights because often social media was the source of name-calling. These quotations suggest that social media amplified the role of namecalling between college women. It is interesting to note that when focus group participants discussed the role of social media in terms of name-calling and fighting to build and defend a gendered reputation, there were distinct gender differences. This conversation on social media clearly emphasizes that it is mostly college women who utilize social media in terms of name-calling and fighting. Given the complexities in gender differences in how young people use social media, this topic needs further discussion in future studies ${ }^{4}$.

\footnotetext{
${ }^{4}$ For more information on gender differences in the use of social media, see Harquail, C.V. (2010). "Facebook for Women vs. Facebook Designed by Feminists: Different vs. Revolutionary." In Shaw, S.M., \& Lee, J. (5 $5^{\text {th }}$ eds.), Women's Studies: Perspectives and Practices (36-38). NY: McGraw-Hill.
} 
As indicated previously, although verbal insults were instrumental to college women's fights being perceived as building and defending their gendered reputation, they still risked damage to their reputation for participating in fights. When verbal insults were continuous prior to a fight between college women, the fight was more likely to be perceived as building and defending their gendered reputation. For example, one focus group participant from the previous conversation suggests that fights between college women are less spontaneous and more likely to be planned because she explains, "she's gonna make that decision of 'oh she's gonna jump her' or there's gonna be a [verbal] fight prior to that actual fight."

The following passages further support the notion that verbal insults are important to college women's fights being perceived as building and defending their gendered reputation. These passages further reveal that fights between college women were often perceived as being the result of a prolonged exchange of verbal insults rather than a brief altercation.

"It's not feminine -I would say it's not considered feminine to fight. Probably the reason you see it a little less. It's not considered feminine." -Male, 19

“...A feminine trait [is] to be more passive and I feel like a lot of female fights they had been personally attacked verbally beforehand such as 'oh she called me a bitch.' Well I can't have people thinking that it's okay for her to call me a bitch', or 'I need to do something about this..."' -Female, 19

“Female fights are two girls who've had a problem with each other for a really long time. They go back and forth, they bicker, they call each other 
names, maybe there was a past guy that they had some tiff with, but it's definitely a long drawn out thing of tension and then it just kind of blows up." -Female, 18

The above conversation indicates that many focus group participants agreed that in certain situations, such as when college women were verbally insulted and have "had a problem with each other for a really long time", fighting was perceived as important to building and defending their gendered reputation.

In terms of verbal insults and college women fighting to build and defend their gendered reputation, some focus group participants believed that insults related to a woman's physical appearance were more likely to spark fights. The following quotation reinforces this finding:

"Another thing, the worth of the man is placed in his physical strength so it is an actual physical exertion of his strength to be in a fight. Whereas a women's worth is placed on her appearance and her ability to be feminine, dainty, etc. and to fight, it kind of goes against this to act more masculine, to act more... aggressive and rashly." -Female, 20

The previous quotation suggests that insults that jeopardize a college woman's femininity are the insults most worth defending because her emphasized femininity is at risk. Although fighting is a traditionally masculine behavior, when a college woman's femininity is challenged, the current findings suggest that fighting is one way to repair her damaged reputation. Recall from the chapter on femininities and women's aggression that physical appearance is central to college femininity which includes being "cute" and being sexy not slutty (Armstrong \& Hamilton, 2013). With college femininity linked so closely to physical appearance, it makes sense that insults regarding physical appearance are perceived as the most important to 
defend in terms of a college woman's gendered reputation. While it is interesting to note that focus group participants linked college femininity, physical appearance, and the role of insults in fights between college women, this theme was not present in all of the focus groups and needs further exploration in future studies.

During the focus groups, terms such as "trashy" and "classless" were sometimes used to denote that when college women participate in fights, they break traditional feminine gender norms. However, if college women were defending their gendered reputations against previous verbal insults, the behavior was often justified. In other words, college women who fight can be perceived as deviant (denoted by labels such as "trashy") because their behavior breaks traditional feminine gender norms, unless they fight to defend their gendered reputation against verbal insults. Responses from focus group participants in the current study support Armstrong and Hamilton's (2013) work on college femininity in that both studies suggest that verbal insults such as "slut" are used to establish college women's deviation from traditional feminine gender norms.

The findings on the role of verbal insults in terms of college women who fight can also be traced to previous literature that suggests that women who break gender norms are often labeled "mad or bad" (Belknap, 2007; Chesney-Lind, 1986; Gilbert, 2002). In this "mad or bad" framework, women who break traditional feminine gender norms for a variety of reasons, including being aggressive, are perceived and labeled as crazy or deviant (Belknap, 2007; Chesney-Lind, 1986; Gilbert, 2002). Similarly, the findings for this thesis suggest that when college 
women fight they risk negative labels that indicate their deviance. However, the findings from this thesis do not fully align with the mad or bad framework. Focus group participants believed that when college women defended their gendered reputation against verbal insults, especially ongoing verbal insults and insults against physical beauty, often their behavior was likely to be justified because it serves to build and defend their gendered reputation. When verbal insults are exchanged prior to a fight between college women, often they are not perceived and labeled crazy or deviant.

\section{The Role of Friends}

Another aspect of why college women fight in terms of their gendered reputation deals with seeking encouragement and validation from their friends. Ness' (2004) study of fights between urban girls and women suggests that often before and during fights friends would "egg her on" (Ness, 2004: 44). Similar to the findings from Ness (2004), focus group participants in the current study discussed the important role of friends in terms of college women fighting to build and defend their gendered reputation. Focus group participants explained that often when college women fight, their friends would offer verbal encouragement. Focus group participants further explained that when college women who fight received encouragement and validation from their friends, often their behavior was perceived as building and defending their gendered reputation. 
The following focus group data highlight the idea that when college women fight, support from their friends is critical in terms of building and defending their gendered reputation:

"I've heard women fighting on the street, not physical fighting, verbal fighting and that kind of building up. Taking off the shoes and earrings, and I've heard their girlfriends be like 'Hey Jennie it's not worth it, it's not worth it, drop it.'” -Male, 19

"It would probably depend on the offensive quote... If it's bad enough, your friend is gonna be like 'yeah, she deserves her assed kicked...'”-Female, 20

[They have to think more about how this is going to negatively affect their status, 'is it worth it?]

"Exactly." -Female, 18

"A girl has to be very, it has to be a serious issue for a girl to fight another girl... Asking her friends and all that stuff versus guys... if a guy looks at him wrong and there's this hyper masculine, machismo, ego thing and they're likely just to have a little fight. With women it's just so drawn out, something's happened and they're so insulted..." -Female, 18

The above passage indicates that when college women fight, often they will receive encouragement and validation from friends. For example, one focus group participant from the above conversation explained that in a fight between college women, a friend might indicate that an opponent "deserves her assed kicked." Additionally, a college woman may feel validated to fight when friends believe that whatever the opponent did is considered "bad enough" to potentially create a 
serious mark against her gendered reputation. Similar to the urban girls and women in Ness' study (2004), when college women fight, encouragement and affirmation from friends serves to justify a fight as a way to build and defend a gendered reputation. The previous quotations additionally indicate that focus group participants believed that college men could get into fights spontaneously, for trivial reasons, and without weighing heavily the consequences to their gendered reputations. Meanwhile, college women must weigh the perceived pros and cons of participating in a fight in terms of their gendered reputations. One manner in which college women gauge whether or not their participation in a fight will be perceived as building and defending their gendered reputation is if they have encouragement and approval from friends.

\section{Explanations After the Fight}

In addition to the encouragement friends provide, focus group participants also believed that college women consulted their friends after a fight as a way to explain their behavior. As the previous passage from the data demonstrates, focus group participants believed when college women fight they must weigh the consequences of their behavior much more than college men. Focus group participants also believed that college women were held more accountable after fights occur. A quotation used in the previous chapter on findings for college men suggests that when college men fight they can continue a night of partying:

“...With the frat and groups that are used to being in constant fighting, it seems like they can go out to the club, have a fight, go back to another club, rage some more, maybe get into another fight, then go home and the fight 
doesn't ruin their night 'cuz I guess they're just so use to it. Again my roommate that's in a well-known frat will get into two, three fights a night and just have a great night and it doesn't ruin it." -Male, 19

Meanwhile college women must weigh the consequences of their behavior and often explain it afterward, especially if the fight serves to build and defend their gendered reputation. The following quotation further supports the notion that when college women fight to build and defend their gendered reputation, they seek to explain why they participated in the fight afterward:

"Another thing that I've heard with women and when they've been in a fight, they have to tell why they were in a fight. Men it's like 'I kicked his ass', women are like 'she slept with my boyfriend so that's why I beat her ass.'” Female, 20

The speaker in this quotation explains a significant gender difference in how college men and women describe fights they have participated in. College men tell what they did while college women tell what they did and why.

For college men, participating in a fight is almost always perceived as building and defending their gendered reputation regardless of the circumstances, unless they show emotion. For college women, participating in a fight is perceived as building and defending their gendered reputation when they have justification for their behavior. When college women fight to defend their reputation against verbal insults, because they have encouragement from their friends, or when women can explain why afterward, their behavior is often justified. These gender differences in perceptions of college students who fight to build and defend a gendered reputation make sense given the links between aggression and gender norms. Masculine gender norms link boys and men's behavior with aggression and 
fighting so that the two become almost synonymous (Connell, 2000; Kimmel, 2008). For college women, participating in a fight is also perceived as building and defending their gendered reputation. However, because the link between physical aggression and femininity is weak at best, college women must justify and explain their participation in fights if it is to build and defend their gendered reputations.

The following section is unique in that it will focus on college women who fight to build and defend their gendered reputation and resist emphasized femininity. The following section suggests that when some college women fight, their behavior is perceived as building and defending their gendered reputation independent of justifications and explanations. When college women take pride in fighting because they self-identify with some of the previously mentioned verbal insults ("ratchet," "trashy," etc.), their participation in fights is still perceived as serving to build and defend their gendered reputation. However these women seem to lack the need to justify and explain their behavior.

\section{Taking Pride in Risky Behavior: The "Ratchet" Woman}

When college women who fight self labeled as "ratchet" or "not very classy", focus group participants believed their fights served to build and defend their gendered reputation regardless of whether they justified or explained their behavior. According to the Urban Dictionary, "ratchet" refers to the most non-classy individuals in a social situation and someone who is always trying to pick fights 
("Urban Dictionary", 2013). ${ }^{5}$ In recent years ratchet has been re-appropriated (the process where groups or individuals take possession of a negative label previously used by a dominant group to denote lesser status), especially in popular culture. Focus group participants explained that college women who re-appropriated words such as "ratchet" and "trashy" took pride in their fights. Rather than fighting to build and defend their gendered reputation against verbal insults, college women who reappropriate traditional verbal insults took pride in their fights. Fights between these women were perceived as building and defending their gendered reputation because of their self-established reputation as "ratchet" rather than because their reputation was already damaged. In one focus group, participants elaborated on the type of college women who takes pride in fighting:

"I would say only in a negative way, as opposed to with men, you know, you fight and you can really do some damage. It's like 'wow that guy's a real man.' For women it's like 'oh yeah she's a little, you know, she's a little fighter, she's a whore."' -Male, 18

"I feel like there's two different mentalities though because..." -Female, 18

“The way I look at fighting with women is I just don't think it's very reputable. I just don't think it's a very classy thing. But I know some girls that will, I know this one girl who will label herself as ratchet. That's part of her identity, and she's proud of it. She would be more proud to get in a fight than I would." -Female, 18

\footnotetext{
${ }^{5}$ For a more thorough overview of women's reappropriation of gender labels, see Galinsky, A., Wang, C., Whitson, J., Anicoch, E., Hugenberg, K., \& Bodenhausen, G. "The Reappropriation if Stigmatizing Labels: The Reciprocal Relationship Between Power and Self-Labeling" (2013).
} 
“Fighting for women, from what I've always heard, it was always in a negative manner. A guy is like 'yeah dude, my bro got into this fight and won yeah!' It's very celebratory. For women it's like 'Yeah, Jennifer got in a fight and I don't know what she did, but it's so trashy.' Again trashy, ratchet, whatever the word you wanna use. It's considered, they use the phrase classy, it's this image of this woman being this angel or prestigious or she's kind of tucked away. But when she fights it's 'oh well she's trying to do stuff."' -Male, 19

The beginning of this passage reiterates the findings that the perceptions of many college students are influenced by traditional gender norms such as women should not fight and fighting is unfeminine. The beginning also supports the notion that when college women fight, peers often label them as "classless" or "trashy." However, the focus group participants indicated that there is an alternative "mentality," and the passage explains that some college women take pride in fighting.

Similar to Ness' (2004) study on urban girls and women's aggression, when college women self-identify with an alternative form of femininity (urban women identifying as "tough" and college women identifying as "ratchet"), their participation in fights is perceived as building and defending their gendered reputation. When college women self-identify with labels such as "ratchet," regardless of whether or not they justify their participation in a fight, the behavior is likely to be perceived as building and defending their gendered reputation.

If college women who re-appropriate words such as "ratchet" and "trashy" unapologetically participate in fights (i.e. there is no justification such as prior verbal insults or approval seeking from peers), the implication is that they are 
adhering to an alternative femininity because fighting and aggression is not traditionally feminine behavior (Campbell, 1993; Connell, 2000; Jack, 1999). Previous studies that explore college women's femininity suggest that they must adhere to traditional feminine gender norms (Armstrong \& Hamilton, 2013). However, this finding from the current thesis suggests that for some college women, an alternative to traditional femininity exists. In this alternative femininity, college women re-appropriate labels such as "ratchet," they take pride in their fights, and their fights are perceived as building and defending their gendered reputation. Similar to women who have masculine professions, working-class women who fight, and urban woman who fight, this thesis suggests that an alternative femininity exists for some college women. Future research must further explore the implications of college women who resist emphasized femininity. This will provide insight into an alternative femininity within the context of the college campus.

The end of this passage provides further support for the notion that when college women fight, verbal insults are key to their peers perceiving that the fight serves to build and defend their gendered reputation. It is clear from these quotations that words such as "whore" and "slut" are still used to challenge a college woman's femininity instead of strictly signifying her promiscuity. However, when these insults are used, fighting can be a strategic way for college women to build and defend their gendered reputation against verbal insults. As the last speaker indicated, when college women fight there will be arguing and "bickering" prior to the fight because the expectation is that prior verbal insults almost always occur before two college women fight. While focus group participants believed that college 
women who re-appropriate words such as "ratchet" and take pride in fighting might not justify or explain their behavior, this is not the case for many college women who fight to build and defend their gendered reputation.

This chapter explores the way college students perceived college women who engage in fights in terms of building and defending their gendered reputation. In many ways focus group participants were influenced by traditional gender norms that women should be physically passive. Some focus group participants even believed that fights between college women were "unnatural" while other focus group participants believed that when college women fight they are perceived as deviant and labeled "classless" or "trashy." Although these traditional gender norms persist and influenced the way college students perceived fights between college women, the findings for this thesis also suggest that there are certain situations where fights between college women are acceptable by their peers. Under these circumstances, college women can fight to build and defend their gendered reputation.

The findings of this thesis regarding college women's use of physical aggression suggest that their fights do serve to build and defend their gendered reputation, but in a different way from college men. Gender differences in the perceptions of fights between college men and between college women derive from traditional gender norms regarding aggression. When focus group participants described fights between college women, their descriptions were often influenced by traditional gender norms in that they often used language such as unnatural, 
trashy, and slutty. Although college students sometimes negatively label college women who fight, when a college woman's status was already under attack via verbal insults, it was often perceived as acceptable for her to participate in a fight to build and defend her gendered reputation. Additionally, when college women fight and they receive encouragement and validation from friends, when they explain the fight afterward, or when they take pride in fighting, their fight is often perceived as a way to build and defend their gendered reputation.

Meanwhile, fights between college men are almost always perceived as a way to build and defend their gendered reputation. When college men fight they build and defend their gendered reputation because it serves to prove their masculinity, they make a need for a fight, and they fight to perform masculinity. The only time participating in fights can have damaging consequences for college men is when they show emotion during a fight. College students perceived gendered reputation as an important reason for explaining why both college men and women fight on campus. However, college students' perceptions in terms of how fighting contributes to an individual's gendered reputation differs based on the gender of fight participants. The implication is that many college fights are similar in that they serve to build and defend gendered reputation. Yet, depending on the gender of the fight participants, the perceptions of the circumstances surrounding how fighting serves to build and defend an individual's gendered reputation are different. It is unclear from the current data whether students perceived fights as different exclusively because of pervasive gender norms, or because there are significant gender differences in how college students fight. 
A quick reference to the literature suggests that it is possible that because men and women are socialized differently, and college masculinity and femininity still looks very different (similar to traditional notions of masculinity and femininity), college men and women fight differently and for different reasons (Armstrong \& Hamilton, 2013; Campbell, 1993; Kimmel, 2008). However, because fights between both college men and women are common and often normalized by students on campus, it is also possible that their behavior is more similar and perceived as different (Weiss, 2013). This idea that fights between college men and women are similar but perceived as different is comparable to studies on urban girls and women's use of fights as well as studies on women who engage in other types of untraditionally feminine behavior such as having a masculine profession. Recall from the chapter on femininities and women's aggression that Ness (2004) suggests that often when urban adolescents fight and engage in aggressive behavior, the behavior is similar but is assigned different causal factors. Similarly, Boldry et al. (2001) suggest that when men and women in the military both have the same role and engage in the same behavior, their behavior is perceived differently where peers describe men as better leaders than women.

In terms of understanding how college students perceive building and defending a gendered reputation as an important reason for explaining why their peers fight, there were a variety of reasons for both college men and women. The findings of this thesis suggest that college students perceive fighting as a way for college men to build and defend their gendered reputation when they prove their masculinity, when they make a need for a fight, and when they fight to perform 
masculinity. Additionally, the findings for college men suggest that when they lose a fight and show emotion, they risk damage to their gendered reputation. For college women, the findings of this thesis suggest that college students perceive fighting as a way to build and defend their gendered reputation during four different circumstances. When college women fight to restore their gendered reputation because it has already been damaged verbally, when they have encouragement from their friends, when they justify their participation in a fight afterward, and when they re-appropriate traditionally negative labels and take pride in fights, fighting serves as a way to build and defend their gendered reputation. Although focus group participants perceived both college men and women's fights as serving to build and defend their gendered reputation, the way they understand fighting as a way to build and defend a fight participant's gendered reputation varies based on the gender of the fight participant. 


\section{Chapter 7: Conclusion}

This thesis applies a micro level approach to understanding gender, gender norms, masculinities, and femininities in the context of fights in the college party subculture. Specifically, this thesis focuses on these concepts in terms of college students' perceptions of gender and fighting on college campuses. This thesis uses focus group data to explore how college students perceived building and defending a gendered reputation as an important reason for explaining why college men and women fight. The current study expands upon previous studies that focus on the behavior of college students (Armstrong and Hamilton, 2013; Kimmel, 2008; Weiss, 2013), and found that while fights between college men and college women were perceived differently by their peers, building and defending a gendered reputation was perceived as explaining one aspect of why both college men and women fight.

Using West and Zimmerman's (1987) work on “doing gender”, Butler's (1988) work on gender performance, and Connell's (2000) work on hegemonic masculinity and emphasized femininity as a framework, this thesis explores gender norms related to aggression and the way these concepts influenced perceptions of fights on the college campus. This thesis also explores the literature on gender and aggression as well as the college party subculture, college masculinity, and college femininity to better understand the context of college fights. In all three focus groups gender norms about aggression and fighting influenced the perception of interviewees. This thesis explores the question how is building and defending a gendered reputation perceived by college students as an important reason for 
explaining why college men and women fight? The findings from this thesis reaffirm previous studies that suggest fights occur, are common, and often normalized on the college campus for both college men and women (Kimmel, 2008; Weiss, 2013). The current findings build upon previous literature and suggest that not only are fights normalized by students, they are perceived as a way for both college men and women to build and defend their gendered reputation in a variety of circumstances.

When college men fight, their behavior is often perceived as a way to build and defend their gendered reputation in that they often fight to prove their masculinity, they make a need for fights, and they fight to perform masculinity. However, if college men showed emotion, especially after losing a fight, their participation could negatively impact their gendered reputation. Findings for college women were similar in that fighting was perceived as important to building and defending their gendered reputation under certain circumstances. However, the circumstances for college women were different than those for men. These circumstances include when college women defend their gendered reputation against verbal insults, when their fights are encouraged by friends, when women are able to explain why they participated in a fight afterward, and when women selfidentify with labels such as "ratchet" and take pride in fighting.

The findings of this thesis regarding college men's use of fights to build and defend a gendered reputation support previous literature including literature on traditional masculine gender norms and literature on college masculinity (Campbell, 1993; Connell, 2000; Kimmel, 2008). Studies on traditional masculine gender 
norms and on college masculinity suggest that men should engage in aggressive behavior in order to demonstrate and prove masculinity (Campbell, 1993; Connell, 2000; Kimmel, 2008). Throughout all three focus groups, participants repeatedly explained that for college men, proving their masculinity played a key role when participating in fights. Additionally, focus group participants believed that college men often make a need for fights as a way to prove their masculinity. By making a need for a fight and participating in a fight to prove their masculinity, college men are able to tell the story of their fight which in turn continues to build and defend their gendered reputation.

Findings from this thesis also suggest that in terms of fighting to build and defend a gendered reputation, college men use fights as a way to perform gender. This finding is similar to Kimmel's (2008) work in Guyland in that both studies highlight the importance of performing masculinity for other college students in the context of the college campus. This finding regarding college men fighting to perform masculinity also draws upon West and Zimmerman (1987) and Butler's (1988) work on "doing gender" and gender performance respectively.

Although typically for college men fights served to positively influence their gendered reputation, the findings from this thesis also suggest that when they lost a fight or showed emotion, their participation would negatively influence their gendered reputation. Because showing emotion and weakness are behaviors uncharacteristic of college masculinity, it makes sense that these behaviors are risky to a college man's gendered reputation. The findings from this thesis regarding 
college men who fight and their gendered reputation speak to one reason why fights between college men persist. Even though losing a fight can be perceived negatively, college men are willing to take this risk and fight in order to build and defend their gendered reputation.

The findings of this thesis regarding college women's use of aggression suggest that their fights serve to build and defend their gendered reputation but in a different way than college men. When focus group participants described fights between college women, their descriptions were often influenced by traditional feminine gender norms such as women should be physically passive during confrontation (Campbell, 1993). For example, one focus group participant explained that fights between college women were perceived as "unnatural" because women are taught to behave passively. Although college women who fight were sometimes perceived as "classless" and "trashy," when a college woman's status was already under attack via verbal insults, it was often perceived as acceptable for her to fight to build and defend her gendered reputation.

The findings for college women who fight support previous literature on women's aggression and fighting. Studies on fights between urban women and working-class women suggest that women fight in part because of name-calling or because they receive validation from friends. Additionally, some women -those who identified with certain labels -take pride in fighting (Day et al., 2003; Ness, 2004). In this thesis, the findings on perceptions of college women's fights also support literature on gender norms for college women in that focus group participants 
linked women's use of fights in terms of their gendered reputation to college femininity including the importance of physical appearance (Armstrong \& Hamilton, 2013).

It is important to note that in all but three of these circumstances, college women who fight must justify and explain their behavior in order for it to be perceived as building and defending their gendered reputation. The exception is when college women re-appropriate certain words and take pride in fighting. In this fourth circumstance, college women who fight represent an alternative to emphasized femininity (i.e. traditional feminine gender norms), and their fights are perceived as building and defending their gendered reputation without justification or explanation. Meanwhile, the findings for college men suggest that they can fight to build and defend their gendered reputation without justifying their behavior. While traditional gender norms clearly still resonate with college students and their perceptions of fights on campus, it does appear that some college women are able to successfully demonstrate an alternative to emphasized femininity when they fight to build and defend their gendered reputation.

Previous studies suggest that college women are expected to adhere to traditional feminine gender norms as well as norms of the party school (Armstrong \& Hamilton, 2013). In many ways these two sets of norms are contradictory because college women are expected to be introverted, but the college party subculture typically values extroverted behavior and risky behavior (Armstrong \& Hamilton, 2013; Weiss, 2013). Future research that explores perceptions of gender and college 
fights on a variety of campuses should pay careful attention to college women's use of fights in terms of building and defending their gendered reputation. In doing so, researchers may be able to determine whether alternatives to emphasized femininity exist in other college environments, or if there is something unique about the norms of party schools that provide some college women with an alternative to emphasized femininity.

The relationship between the gender of fight participants and fighting to build and defend a gendered reputation is important to understanding why fights occur on college campuses. When fights between college men and women are perceived as a viable way to build and defend their gendered reputation under certain circumstances, this provides one possible explanation for why college students continue to fight. Given the significance of demonstrating appropriate masculinity and femininity in college, it makes sense that college fights persist despite the potential for serious injury (Weiss, 2013). It is of particular interest to understand college women's involvement in fights because their use fighting is often minimized given the constraints of traditional feminine gender norms (Armstrong \& Hamilton, 2013; Campbell, 1993; Jack, 1999). While traditional feminine gender norms continue to influence the perceptions of college students, college women seem to be resisting emphasized femininity in part by re-appropriating negative labels and taking pride in their fights that serve to build and defend their gendered reputation. 
Because the findings from this thesis are exploratory, they are limited. As discussed in the research objectives and methods chapter, the focus group data collected for this thesis are not representative and may not generalize to all colleges. Often when focus group data are used in studies, the data serve to provide researchers with findings that can better develop future research projects. Because focus groups often help shape future data that is more representative, the data for this thesis should provide a foundation for impending studies. In the future, studies on gender and fighting on college campuses should include more in-depth questions in terms of race and ethnicity and social class. Also, further studies should focus on other types of colleges such as smaller liberal arts schools and commuter colleges.

In terms of race and ethnicity the current study has two major limitations. The sample for the current data lacked diversity and over-represented black students. Additionally, the focus group questions were not designed to address race and ethnicity in-depth. During focus groups race was briefly discussed, but the topic was not a recurring theme because the questions did not foster this topic. In Ness' study (2004) on inner city fights, race was described as being central to understanding why girls and women fight. While the current study is limited and does not speak to the role of race in terms of understanding gender and fighting on the college campus, the topic did surface. Future research with a more diverse sample should provide in-depth responses to questions related to race and ethnicity in order to better understand the role race and ethnicity plays in perceptions of college men and women's fights. 
Another important demographic variable that should be further explored in future studies is social class. In this thesis, the findings on college women's fights and gendered reputation indicate that sometimes when college women fight, they are labeled "classless." Although some focus group respondents hinted at the term social class when discussing labels such as "classless" and "trashy," it is unclear if these labels suggest that college women who fight are perceived as being from a lower economic class. The Day et al. (2003) study on working-class British women who fight provides a foundation for better understanding gender, social-class, and fighting. However, this study focuses mostly on working-class women rather than providing insight into a variety of social classes. Additionally, Armstrong and Hamilton's study (2013) on college women who party provides insight into the ways in which social class is amplified in terms of social situations on the college campus. Yet, Armstrong and Hamilton's (2013) study provides little insight into the implications of social class in terms of gender and fights on the college campus. Little research has focused exclusively on college women, social class, and fighting, yet previous studies have established that social class is important in terms of understanding both gender and fighting and women in college. Future research should build upon this thesis and bridge the gap in previous literature by focusing on gender, class, and fighting in addition to race and ethnicity.

When focus group participants discussed fights between college women and the role of verbal insults, they often brought up social media. Respondents explained that for college women, social media has become a popular way to insult another woman's femininity and damage her gendered reputation. For college women, 
verbal insults on social media can often result in a fight. When developing questions for the focus groups, I did not anticipate the significant role of social media in college women's fights; the facilitator questions reflect that. This thesis suggests that there is a distinct difference in the way college men and women use social media, and that this gender differences impact the way fights on campus are perceived. Future research should ask more in-depth questions about the role social media plays in terms of gender and fighting on the college campus.

By focusing on the importance of fighting and gender reputation, this thesis focuses exclusively on one aspect of why college men and women fight. Future research should explore the way gender norms influence perceptions of other motivations for college fights such as fighting over potential romantic partners. If college administrators better understand how and why fights occur and are common on campus, especially in regard to gender norms, they can develop more effective prevention and intervention strategies for witnesses, fight participants, and authority figures such as police officers. More effective prevention and intervention strategies should address gender differences in perceptions of why college students fight.

As the student newspaper indicates, when fights on campus commonly occur, some students become concerned about their safety because of the potential for injury. Even if other college students are not concerned for safety because they normalize fights and perceive fights as important in building and defending their gendered reputation, the reality is that fights often result in injury (Weiss, 2013). 
Because fights are a source of concern for some college students and cause injury for others, it is important that college administrators better understand the unique way gender influences perceptions of fights. As this thesis indicates, gender is an important influence on students' perception of why college students fight so gender as well as other demographic characteristics should continue to be the focus of future studies. Even though college students' perceptions of fights are often different based on the gender of the fight participants, as one focus group participant explained:

"I bet it's more similar than we ever realize. But at the same time I think we'll never really understand each other you know? Men and women have this idea that somehow we're different..." -Male, 19

This last quotation indicates that although college students often perceive fights as different based on gender norms regarding aggression, the behavior of college men and women who fight is often more similar than students realize. This quotation also suggests that the way college students perceive fights is more complicated because it may differ from the reality of these confrontational situations. Through future research, a better understanding of the complexities behind gender and fighting on the college campus can be achieved and can result in safer college campuses. 


\section{References}

Armstrong, E. A., \& Hamilton, L. T. (2013). Paying for the Party: How College Maintains Inequality. Harvard University Press.

Belknap, J. (2007). The Frequency and Nature of Female Offending: The Invisible Woman: Gender, Crime, and Justice. $3^{\text {rd }}$ ed. Belmont: Thomas Wadsworth, 95-142.

Benson, D., \& Archer, J. (2002). An Ethnographic Study of Sources of the Conflict Between Young Men in the Context of the Night Out. Psychology, Evaluation \& Gender, 3-30.

Boldry, J., Wood, W., \& Kashy, D. A. (2001). Gender Stereotypes and the Evaluation of Men and Women in Military Training. Journal of Social Issues, 57 (4), 689-705.

Brown, L. M., \& Tappan, M. B. (2008). Fighting Like a Girl Fighting Like a Guy: Gender Identity, Ideology, and Girls at Early Adolescence. The intersections of personal and social identities. New Directions for Child and Adolescent Development, 120, 47-59.

Butler, J. (1988). Performative Acts and Gender Constitution: An Essay in Phenomenology and Feminist Theory. Theatre Journal, 40(4): 519-531.

Campbell, A. (1993). Men, Women, and Aggression. New York, NY: HarperCollins Publishers, Inc. 
Chesney-Lind, M., \& Jones, N. (2010). Fighting for Girls: New perspectives on gender and violence. Albany, NY: State University of New York Press.

Chesney-Lind, M. (1986). "Women and Crime": The Female Offender. Signs, 12(1), 78-96.

Cobbina, J.E., Like-Haislip, \& T.Z., Miller, J. (2010). Gang Fights Versus Cat Fights: Urban Young Men's Gendered Narratives of Violence. Deviant Behavior, 31: 596-624.

Connell, R.W., (2000). The Men and Boys. Los Angeles, CA: University of California Press.

Day, K., Gough, B., \& McFadden, M. (2003). Women Who Drink and Fight: A Discourse Analysis of Working-class Women's Talk. Feminism and Psychology, 13(2): 141-158.

Galinsky, A., Wang, C., Whitson, J., Anicoch, E., Hugenberg, K., \& Bodenhausen, G. (2013). The Reppropriation of Stigmatizing Labels: The Reciprocal Relationship Between Power and Self-Labeling. Psychological Science, 24(10): 2020-2029.

Gelder, K., \& Thornton, S. (1997). The subcultures reader. New York, NY: Routledge. Gilbert, P.R., (2002). Discourse of Female Violence and Societal Gender Stereotypes. Violence Against Women, 13(2): 1271-1299.

Greig, A., Kimmel, M., \& Lang, J. (2000). Men, Masculinities \& Development: Broadening our work towards gender equality. Gender Development Monograph. Series No., 10. 
Harquail, C.V. (2010). “Facebook for Women vs. Facebook Designed by Feminists: Different vs. Revolutionary." In Shaw, S.M., \& Lee, J. (5 $5^{\text {th }}$ eds.), Women's Studies: Perspectives and Practices (36-38). NY: McGraw-Hill.

Jack, D. C. (1999). Behind the mask: Destruction and creativity in women's aggression. Harvard University Press.

Kimmel, M. (2008). Guyland: The perilous world where boys become men. New York: Harper.

Krueger, R. A. (2009). Focus groups: A practical guide for applied research. Sage.

Kvale, S. \& Brinkmann, S. (2009). Interviews: Learning the craft of qualitative research interviewing. Thousand Oaks, CA: Sage Publications, Inc.

Lowe, R. D., Levine, M., Best, R. M., \& Heim, D. (2012). Bystander Reaction to Women Fighting Developing a Theory of Intervention. Journal of interpersonal violence, 27(9), 1802-1826.

Morgan, D. (1997). Focus groups as qualitative research. Thousand Oaks, CA: Sage Publications, Inc.

National Center for Education Statistics. (2014). The Condition of Education. Retrieved from http://nces.ed.gov/programs/coe/indicator_cha.asp

Ness, C. D. (2004). Why Girls Fight: Youth Violence in the Inner City. Annals of the American Academy of Political and Social Science, 595, 32-48.

Urban Dictionary. (2013). Urban Dictionary. Retrieved from 
http://urbandictionary.com/define.php?term=Rachet

Wechsler, H., \& Wuethrich, B. (2002). Dying to Drink: Confronting Binge Drinking on College Campuses. Rodale.

Weiss, K.G. (2013). Party School: Crime, campus, and community. Boston, MA: Northeastern University Press. Print.

Weiss, K.G., \& Liebreich, H. (2013, August). The Situational Normativity of Fighting While Intoxicated (An exploration of "hot spot fights). Paper presented at The Society for the Study of Social Problems Annual Meeting, New York, NY.

West, C., \& Zimmerman, D. H. (1987). Doing gender. Gender \& society, 1(2), 125-151.

West Virginia University College Portrait. (2013). Undergraduate Snapshot. Retrieved from http://www.collegeportraits.org/WV/WVU/characteristics 


\section{Appendix A. Focus Group Protocol}

\section{Introduction:}

Thank you for your participation in this focus group/interview today. Today we will be discussing fights that happen here on campus. Everything that is said during the focus group/interview will be kept confidential.

Fights Between Men:

1. Have you ever witnessed fight between two male students here on campus?

2. How common are fights like this on campus?

3. Describe what happens with a "typical" male-on-male fight.
a. What behavior leads up to the actual physical violence?
b. What do you think starts the fight?
c. For men, does participating in a fight contribute to his self-identity?
d. How long did the fight last?
e. Were the men drunk?
f. Do the participants typically have injuries?
g. What was the most serious fight you've seen?
h. What type of contact do men typically use?
i. Do they punch, wrestling, slap, pull hair etc.?
j. Are weapons typically involved?
$\mathrm{k}$. Overall, how serious do you think the fight was?
l. What about the fight made it seem serious or non-serious
m. Does type of contact, physical appearance such as size or clothing, location of fight make a difference?
n. Does their level of intoxication matter?
o. Was the fight entertaining?
p. What about the fight made it seem entertaining or non-entertaining
q. Does type of contact, physical appearance such as size or clothing, location of fight, etc. make a difference?
r. What did you do?
s. What did others do?
t. How did the fight end?

4. After discussing and thinking about the situation, do you think your reaction was appropriate?

Fights Between Women:

1. Have you ever witnessed a fight between two female students here on campus? 
2. How common are fights like this on campus?

3. Describe what happens with a "typical" female-on-female fight.

a. What behavior leads up to the actual physical violence?

b. I've heard that women will often take off their heels and earrings in preparation for a fight. Have you ever seen this happen?

c. What do you think starts the fight?

d. For women, does participating in a fight(s) contribute to her selfidentity?

e. Does gender matter?

f. How long did the fight last?

g. Were the women drunk?

h. Do the participants typically have injuries?

i. What was the most serious fight you've seen?

j. What type of contact do women typically use?

k. Do they punch, wrestling, slap, pull hair etc.?

l. Are weapons typically involved?

$\mathrm{m}$. Overall, how serious was the fight?

$\mathrm{n}$. What about the fight made it seem serious or non-serious?

o. Does type of contact, physical appearance such as size or clothing, location of fight, etc. make a difference?

p. Does their level of intoxication matter?

q. What about the participants' gender?

r. Was the fight entertaining?

s. What about the fight made it seem entertaining or non-entertaining?

t. Does type of contact, physical appearance such as size or clothing, location of fight, etc. make a difference?

u. What about gender?

v. What did you do?

w. What did others do?

$\mathrm{x}$. How did the fight end?

4. After discussing and thinking about the situation, do you think your reaction was appropriate?

5. Do you think the series of events before after and during a fight differ for men and women?

a. What are some similarities?

b. What are some differences?

6. What are your final thoughts about fighting on campus?

Thank you again for participating in this focus group. 